\title{
Corallina and Ellisolandia (Corallinales, Rhodophyta) photophysiology over daylight tidal emersion: interactions with irradiance, temperature and carbonate chemistry
}

\author{
C. J. Williamson · J. Brodie $\cdot$ B. Goss $\cdot$ M. Yallop · \\ S. Lee $\cdot$ R. Perkins
}

Received: 20 December 2013 / Accepted: 19 June 2014 / Published online: 27 July 2014

(C) The Author(s) 2014. This article is published with open access at Springerlink.com

\begin{abstract}
The photophysiology of three geniculate coralline algal species (Corallina officinalis, C. caespitosa and Ellisolandia elongata) was determined in intertidal rock pools in the south-west UK at Combe Martin $\left(51^{\circ} 12^{\prime} 31 \mathrm{~N}\right.$ $\left.4^{\circ} 2^{\prime} 19 \mathrm{~W}\right)$ and Heybrook Bay $\left(50^{\circ} 31^{\prime} 66 \mathrm{~N} 4^{\circ} 11^{\prime} 41 \mathrm{~W}\right)$, at the start, middle and end of summer (September 1 and 2) and winter (February 9 and 10) daylight tidal emersion periods, in relation to prevailing irradiance, temperature and carbonate chemistry conditions. Algal photophysiology was assessed from rapid light curves performed using pulse amplitude modulation fluorometry. Corallina and Ellisolandia experienced significant fluctuations in irradiance, temperature and carbonate chemistry over seasonal and tidal cycles. Rock pool carbonate chemistry was predictable $\left(R^{2}=0.82, P<0.0001\right)$ by photodose (summed irradiance) plus water temperature, but not significantly related to photophysiology. In contrast, Corallina and Ellisolandia relative maximum electron transfer rate showed a significant negative relationship $\left(R^{2}=0.65, P<0.0001\right)$ with irradiance plus water temperature. At a seasonal resolution, photoacclimation to maximize both light harvesting during winter months and photoprotection during summer months
\end{abstract}

Communicated by K. Bischof.

C. J. Williamson $(\bowtie) \cdot$ B. Goss $\cdot$ S. Lee $\cdot$ R. Perkins

School of Earth and Ocean Sciences, Cardiff University,

Park Place, Cardiff CF10 3YE, UK

e-mail: williamsoncj@cardiff.ac.uk

\section{J. Williamson · J. Brodie}

Department of Life Sciences, The Natural History Museum,

Cromwell Road, London SW7 5BD, UK

M. Yallop

School of Biological Sciences, University of Bristol,

Bristol BS8 1UG, UK was observed for all species. Dynamic photoinhibition was apparent over both summer and winter tidal emersion, in relation to irradiance fluctuations. More effective photoinhibition was apparent during summer months, with greater sensitivity to irradiance and slower recovery in $F_{\mathrm{v}} / F_{\mathrm{m}}$, observed during winter. With sustained high irradiance over tidal emersion, the establishment of high $\mathrm{pH} /$ low inorganic carbon conditions may impact photochemistry. This study represents the first assessment of $C$. officinalis, C. caespitosa and E. elongata photophysiology underpinned by clear species concepts and highlights their ability to adapt to the dramatically fluctuating conditions experienced in intertidal rock pools.

\section{Introduction}

Calcified macroalgae are particularly ecologically important in shallow temperate regions (Johansen 1981). Acting as ecosystem engineers (sensu Jones et al. 1994), they provide habitat for numerous small invertebrates, shelter from the stresses of intertidal life via their physical structure, and surfaces for the settlement of microphytobenthos (see Nelson 2009 for a full review). The Corallinales are the predominant order of calcified macroalgae found in temperate waters and comprise both non-genicluate genera that are mostly encrusting and turf forming geniculate genera (Irvine and Chamberlain 1994; Nelson 2009). In the UK intertidal, turfing species of the genera Corallina and Ellisolandia are epilithic on both exposed substrata and in rock pool habitats (Brodie et al. 2013), where they must tolerate significant fluctuations in abiotic conditions including irradiance, temperature and rock pool water chemistry (Ganning 1971; Truchot and Duhamel-Jouve 1980; Morris and Taylor 1983). 
Irradiance is one of the most important factors controlling the distribution of macroalgae in the littoral zone and also one of the most complex (Luning 1990; Lobban and Harrison 1994). Large fluctuations occur diurnally because of changes in cloud cover, tides and the angle of the sun, and both predictable variability (changes in day length and solar angle) and unpredictable (cloudiness, turbidity and run-off) variability are observed seasonally (Lobban and Harrison 1994). Within the intertidal, sessile macroalgae have to cope with the changing irradiance regime, facing serious photostress during tidal emersion when exposed to high irradiances (Davison and Pearson 1996; Häder et al. 1997; Franklin and Forster 1997). Production of reactive oxygen species as by-products of photosynthesis is increased under high irradiance, causing photooxidative damage, which can ultimately lead to pigment bleaching and death (Muller et al. 2001). Macroalgae have thus developed regulatory mechanisms to ameliorate light stress, including adjustment of the antenna size, thermal dissipation of excess excitation energy, antioxidant systems and the fast repair of photooxidative damage (Häder et al. 2003).

Temperature is also a key factor governing both the large-scale geographical distribution of macroalgal species and the small-scale vertical distribution of species on a shore (Luning 1990) and is of high importance when discussing rock pool ecology (Ganning 1971). In rock pools, temperature is closely related to local climate, especially air and ambient seawater temperature, irradiance, wind, the time of day at which low tide occurs and the extent of heating or cooling due to wave action (Ganning 1971; Lobban and Harrison 1994). At the level of the individual, temperature has fundamental effects on chemical reaction rates and, in turn, metabolic pathways, with complex interactions with other factors (Lobban and Harrison 1994). For example, in photosynthesis, diffusion rates, carbonic anhydrase (CA) activity and active transport of $\mathrm{CO}_{2}$ and $\mathrm{HCO}_{3}{ }^{-}$are all affected by temperature, and thus temperature will influence the supply of substrate to carbon fixation pathways (Lobban and Harrison 1994).

It has long been established that fluctuations in rock pool water chemistry are apparent due to the interactions between physio-chemical and biological processes (Ganning 1971; Daniel and Boyden 1975; Morris and Taylor 1983). Truchot and Duhamel-Jouve (1980) provided the first analysis of diurnal changes taking place in the carbonate system of rock pools, and Morris and Taylor (1983) extended this work to examine both diurnal and seasonal changes, demonstrating that diurnal fluctuations in $p \mathrm{O}_{2}$, $p \mathrm{CO}_{2}$ and $\mathrm{pH}$ were directly related to the photosynthetic activity of the pool flora and to the respiration of both flora and fauna (Morris and Taylor 1983). More recently, interactions between the carbonate system of seawater and the photosynthesis of macroalgae have been examined. The absence of certain macroalgal species from rock pool habitats has, for example, been attributed to the establishment of adverse high $\mathrm{pH}$ and low inorganic carbon $(\mathrm{Ci})$ conditions due to the photosynthetic utilization of $\mathrm{Ci}$ by Ulva intestinalis in Swedish rock pools (Björk et al. 2004). In shallow water macroalgal habitats $(0-1 \mathrm{~m})$, high $\mathrm{pH}$ has also been shown to have a direct negative effect on the photosynthesis of Fucus vesiculosus, F. serratus, Ceramium rubrum and Ulva sp., not accounted for alone by the low availability of Ci (Middelboe and Hansen 2007a).

Variability in carbonate chemistry is also important with regard to species' responses to future ocean acidification (OA) (Hofmann et al. 2011; Andersson and Mackenzie 2012; Hofmann et al. 2014). With OA, increasing concentrations of dissolved $\mathrm{CO}_{2}$ are shifting the seawater carbonate chemistry equilibrium, increasing hydrogen ion $\left(\mathrm{H}^{+}\right)$ and bicarbonate $\left(\mathrm{HCO}_{3}{ }^{-}\right)$concentrations, and subsequently decreasing the concentration of carbonate $\left(\mathrm{CO}_{3}{ }^{2-}\right)$ available for calcification (Doney 2006; Cao et al. 2007; Doney 2010). These changes are predicted to pose significant negative impacts to calcifying macroalgal species (Harley et al. 2012). As OA proceeds, however, periodic exposure to high $\mathrm{pH}$ conditions may ameliorate some of the negative impacts on calcifying species (Hurd et al. 2011; Anthony et al. 2011; Manzello et al. 2012). In addition, local adaptation of calcifying species to natural $\mathrm{pH}$ variability has been linked to increased resilience to future OA conditions (Wootton et al. 2008; Hofmann et al. 2011; Kelly et al. 2013; Wolfe et al. 2013; Hofmann et al. 2014).

The aim of the present study was to provide an assessment of the in situ photophysiology of three turfing geniculate coralline algal species, Corallina officinalis, C. caespitosa and Ellisolandia elongata, within rock pool habitats, in relation to the irradiance, temperature and carbonate chemistry conditions prevailing over tidal emersion periods. Recent molecular insights into cryptic diversity within the genus Corallina has resulted in (1) the splitting of the well-known $C$. officinalis into two genetically distinct species, C. officinalis and C. caespitosa (Walker et al. 2009), (2) a revised definition of $C$. officinalis and $C$. elongata (Brodie et al. 2013) and (3) the establishment of a new genus, Ellisolandia, containing a single species, E. elongata, previously Corallina elongata (Hind and Saunders 2013). As such, almost no information is currently available on the ecology of $C$. caespitosa [though, see Williamson et al. (in review) and Brodie et al. (2013)], which was likely previously investigated under the name $C$. officinalis, particularly if originating from outside of the NE Atlantic (Williamson et al. in review). These phylogenetic advances allow for an examination of the three species' ecology, underpinned by clear species concepts. In addition, while recent research has examined the potential impacts of OA 
on C. officinalis and E. elongata (Egilsdottir et al. 2013; Hofmann et al. 2012, 2013; Noisette et al. 2013), we still lack a decent understanding of the present-day ecology of these species in situ, particularly in relation to abiotic parameters that will significantly change under a high $\mathrm{CO}_{2}$ world, i.e. temperature and carbonate chemistry.

Observations for the present study were conducted over summer and winter daylight tidal emersion periods at two south-westerly UK intertidal sites. Rapid light curves (RLCs) were performed using pulse amplitude modulation (PAM) fluorometry to assess the actual photophysiology of algae at the time of sampling (Ralph and Gademann 2005; Perkins et al. 2010), as opposed to the theoretical potential of photochemistry, facilitating comparison to ambient irradiance and rock pool water temperature and carbonate chemistry monitored in parallel.

\section{Methods}

\section{Study sites and species distributions}

The photophysiology of Corallina officinalis, C. caespitosa and Ellisolandia elongata and the irradiance, water temperature and carbonate chemistry conditions were monitored over daylight tidal emersion periods during summer (1/2 September 2012) and winter (9/10 February 2013), at upper shore Combe Martin (CM), North Devon and
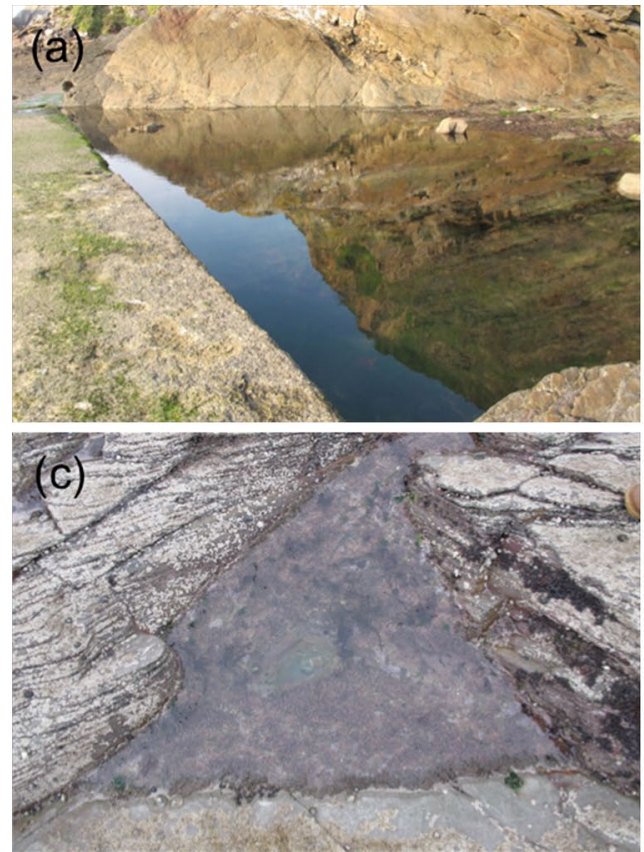

Fig. 1 Examples of sampled rock pools and associated Corallina assemblages. a A typical large upper shore rock pool at Combe Martin (Pool 1) created by man-made walkway, b showing rock pool upper and lower shore Heybrook Bay (HB), South Devon, UK (Fig. 1; Table 1). All sampling was performed on or \pm 1 day of spring tides to allow observation of potential extremes in summer and winter photophysiology and abiotic parameters.

Corallina officinalis is widely distributed around the entire UK, while $C$. caespitosa appears to be more southerly, only occurring on shores in England, and Ellisolandia elongata demonstrates a westerly distribution. At study sites, $C$. officinalis is present at both CM and HB occurring from the lower to the upper shore. Corallina caespitosa is present in upper shore rock pools at CM, where it inhabits a narrow zone (ca. $2 \mathrm{~cm}$ ) at the upper water line of rock pools, $C$. officinalis dominating below this zone. Of the study sites, E. elongata is present in suitable abundances for the present study at lower shore HB only. Field studies were therefore performed at upper shore $\mathrm{CM}(C$. officinalis and $C$. caespitosa present) and upper ( $C$. officinalis present) and lower shore (C. officinalis and E. elongata present) $\mathrm{HB}$, to allow assessment of the three desired species. Species identification was verified by extraction and amplification of the COI gene region and comparison to published sequences of the three species as per Walker et al. (2009) and Brodie et al. (2013).

At upper shore in both $\mathrm{CM}$ and $\mathrm{HB}$, Corallina photophysiology and abiotic conditions were monitored at the start, middle and end of tidal emersion periods in three rock pools (Fig. 1; Table 1). Start and end of the emersion period
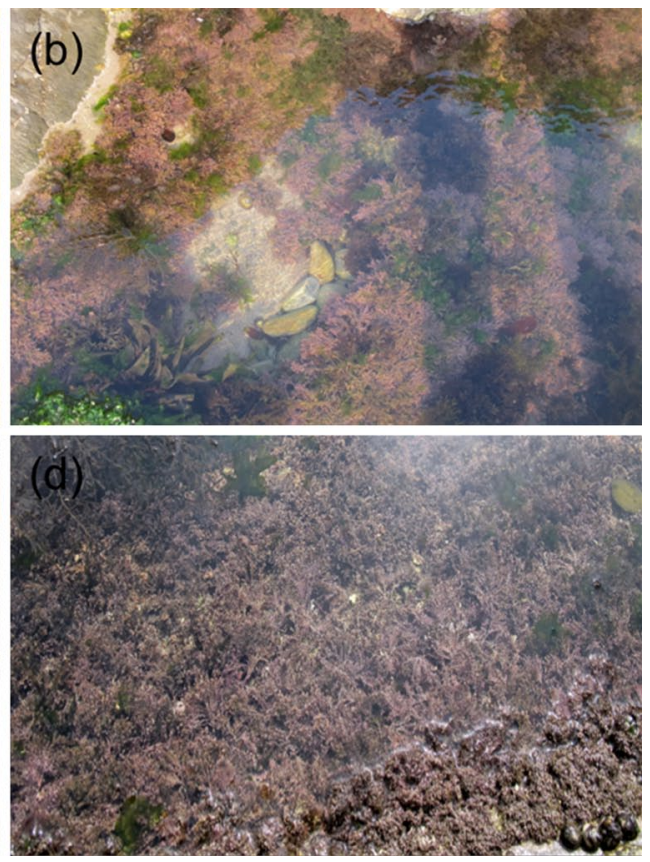

assemblage during summer; $\mathbf{c}$ smaller lower shore rock pool at Heybrook Bay (Pool 1), d showing rock pool assemblage during winter. See Table 1 for rock pool attributes 
Table 1 Site and sampling details

\begin{tabular}{|c|c|c|c|c|c|c|c|c|c|}
\hline & \multicolumn{3}{|c|}{ Combe Martin } & \multicolumn{6}{|c|}{ Heybrook Bay } \\
\hline Location & \multicolumn{3}{|c|}{$51^{\circ} 12^{\prime} 31 \mathrm{~N} 4^{\circ} 2^{\prime} 19 \mathrm{~W}$} & \multicolumn{6}{|c|}{$50^{\circ} 31^{\prime} 66 \mathrm{~N} 4^{\circ} 11^{\prime} 41 \mathrm{~W}$} \\
\hline Tidal range & \multicolumn{3}{|c|}{$\begin{array}{l}\text { MHWS-MLWS }=9.2-0.68(8.52) \\
\text { MHWN-MLWN }=6.9-3.1(3.8)\end{array}$} & \multicolumn{6}{|c|}{$\begin{array}{l}\text { MHWS-MLWS }=5.5-0.8(4.7) \\
\text { MHWN-MLWN }=4.4-2.2(2.2)\end{array}$} \\
\hline Summer sampling date & \multicolumn{3}{|c|}{02.09 .12} & \multicolumn{6}{|c|}{01.09 .12} \\
\hline Summer tides & \multicolumn{3}{|c|}{$06: 48=9.2 / 12: 49=1.1 / 19: 05=9.4$} & \multicolumn{6}{|c|}{$06: 03=5.4 / 12: 12=0.6 / 18: 16=5.6$} \\
\hline Winter sampling date & \multicolumn{3}{|c|}{10.02 .13} & \multicolumn{6}{|c|}{09.02 .13} \\
\hline Winter tides & \multicolumn{3}{|c|}{$05: 51=9.5 / 12: 00=0.8 / 18: 15=9.4$} & \multicolumn{6}{|c|}{$04: 46=5.4 / 11: 12=0.8 / 17: 18=5.3$} \\
\hline Shore height sampled & \multicolumn{3}{|l|}{ Upper } & \multicolumn{3}{|c|}{ Upper } & \multicolumn{3}{|c|}{ Lower } \\
\hline Corallina spp. present & \multicolumn{3}{|c|}{ C. officinalis, C. caespitosa } & \multicolumn{3}{|c|}{ C. officinalis } & \multicolumn{3}{|c|}{ C. officinalis, C. elongata } \\
\hline Pool & 1 & 2 & 3 & 1 & 2 & 3 & 1 & 2 & 3 \\
\hline Height above chart datum (m) & 5.61 & 5.77 & 5.32 & 4.24 & 4.08 & 3.30 & 2.08 & 2.34 & 2.30 \\
\hline Volume $\left(\mathrm{m}^{3}\right)$ & 82.85 & 201.4 & 61.14 & 0.58 & 0.35 & 0.40 & 0.10 & 1.31 & 2.06 \\
\hline Surface area $\left(\mathrm{m}^{2}\right)$ & 165.7 & 493.74 & 181.45 & 5.14 & 3.43 & 2.92 & 0.80 & 13.68 & 15.39 \\
\hline Maximum depth $(\mathrm{cm})$ & 67.0 & 80.0 & 71.0 & 28.9 & 13.8 & 21.5 & 40.6 & 19.8 & 19.8 \\
\hline
\end{tabular}

Tidal range demonstrates mean high/low water spring/neap expressed as range $(\mathrm{m})$. Summer and winter tides report the time and tidal height (m) of high/low/high tides prevailing on sampling days. Lower table summarizes rock pool attributes

were defined as being within $30 \mathrm{~min}$ of tidal isolation (start of emersion) and tidal reconnection (end of emersion) of the rock pool to the main tidal water mass. Mid emersion period was defined as the time midway between the start and end of emersion measurements. At lower shore HB, Corallina and Ellisolandia photophysiology and abiotic conditions were monitored in three rock pools at the start and end of tidal emersion periods only, given the shorter duration of tidal emersion at this shore height. In all cases, rock pools were selected where Corallina and/or Ellisolandia demonstrated $>$ ca. $75 \%$ cover, visually estimated by the authors.

\section{Monitoring of abiotic conditions}

Ambient photosynthetically active radiation (PAR, $\mu \mathrm{mol}$ photons $\mathrm{m}^{-2} \mathrm{~s}^{-1}$ ) was measured three times during each sampling period [start, middle (upper shore only) and end of emersion] per rock pool (total $n=9$ measurements per emersion period), using a 2 pi LI-COR cosine-corrected quantum sensor positioned ca. $5 \mathrm{~cm}$ above the surface of the rock pools. For each recording, a 15-s average was taken using an automated function on the sensor. The average irradiance for the start, middle and end periods of tidal emersion was calculated as the average of all measurements taken across respective sampling periods for all pools. Cumulative photodose (PAR, mol photons $\mathrm{m}^{-2}$ ) was calculated from irradiance measurements by summing PAR over time from the start of tidal emersion of rock pools and calculation to more appropriate units. In parallel, rock pool water temperatures were monitored with a digital thermometer as above.
Collection of water samples for determination of carbonate chemistry followed the methods of Dickson et al. (2007) adapted for coastal fieldwork. During each period of tidal emersion [start, middle (upper shore only), and end], two water samples were collected in 250-ml borosilicate glass bottles (Schott Duran) from approximately $5-\mathrm{cm}$ depth in the centre of each rock pool. $1 \%$ volume $(2.5 \mathrm{ml})$ was discarded to allow for water expansion, and $0.02 \%$ by volume $(50 \mu \mathrm{l})$ of saturated mercuric chloride solution was added to poison the sample. Bottles were immediately closed and sealed with pre-greased, ground-glass stoppers to ensure gas-tight conditions, and bound with electrical tape. Samples were stored in a cool (approximately $4-6{ }^{\circ} \mathrm{C}$ ), dark (no ambient detectable light) location until analysis.

Carbonate chemistry parameters, $p \mathrm{CO}_{2}, \mathrm{pH}, \mathrm{HCO}_{3}{ }^{-}$, $\mathrm{CO}_{3}{ }^{2-}$ and the saturation states of aragonite, $\Omega_{\mathrm{arg}}$, and calcite, $\Omega_{\text {cal }}$, were determined from measurements of dissolved inorganic carbon (DIC) and total alkalinity (TA) performed on all carbonate chemistry water samples by the UK Ocean Acidification Carbonate Chemistry Facility at the National Oceanography Centre, Southampton, UK. DIC was analysed with an Apollo SciTech DIC analyzer (AS-C3), using a LI-COR (7000) $\mathrm{CO}_{2}$ infrared analyser. TA was determined using an open-cell titration (Dickson et al. 2007) with the Apollo SciTech's AS-ALK2 Alkalinity Titrator. For both DIC and TA, the precision was $0.1 \%$ or better and the accuracy was controlled against Certified Reference Materials (A.G. Dickson, Scripps). Carbonate chemistry parameters were calculated with CO2SYS (version 1.05, Pierrot et al. 2006), using the constants of Mehrbach et al. (1973) refitted by Dickson and Millero (1987). 


\section{Corallina and Ellisolandia photophysiology}

The photophysiology of $C$. officinalis, $C$. caespitosa and E. elongata was determined using PAM fluorometry. RLCs (Perkins et al. 2006) were performed using a Walz WaterPAM fluorometer, with three replicate light curves performed per Corallina and/or Ellisolandia species present in each rock pool (Table 1), at the start, middle (upper shore only) and end of summer and winter tidal emersion. Algal fronds were randomly selected from the upper $5 \mathrm{~cm}$ of rock pool walls for RLC analysis to allow some degree of continuity in light field experienced, with the exception of $C$. caespitosa at $\mathrm{CM}$ that is only found in a ca. $2 \mathrm{~cm}$ narrow zone along the upper water line of rock pool walls. RLCs were performed on the tips of fronds to avoid potentially self-shaded frond regions, and care was taken to determine RLCs on the side of fronds facing direct sunlight, as, e.g., the underside of fronds likely demonstrate differential photoacclimation.

RLCs are an effective tool with which to detect the operational photophysiology of a sample at the time measurements are made, providing information on the dissipation of energy from limiting levels of irradiance through to saturating levels, and can act as a proxy for the electron transport rate through photosystem II (Burdett et al. 2012). RLCs differ from traditional $P-I$ curves in that they measure the actual, rather than the optimal, photosynthetic state, as steady state is not achieved during each light step duration (Ralph and Gademann 2005; Perkins et al. 2010).

RLCs were performed using a saturating pulse at a setting of ca. 8,600 $\mu \mathrm{mol}$ photons $\mathrm{m}^{-2} \mathrm{~s}^{-1}$ PAR, for $600 \mathrm{~ms}$ duration, and with nine $30 \mathrm{~s}$ incrementally increasing light steps from 0 to $1,944 \mu \mathrm{mol}$ photons $\mathrm{m}^{-2} \mathrm{~s}^{-1}$ PAR. Light step duration was selected to balance potential photoacclimation occurring during longer light steps $(60 \mathrm{~s})$, with errors associated with shorter light steps (10 s) when samples have been exposed to high light (Perkins et al. 2006). Analysis of RLCs followed Perkins et al. (2006) with iterative curve fitting (Sigmaplot v. 14) and calculation of the relative maximum electron transfer rate $\left(\mathrm{rETR}_{\max }\right)$, the theoretical maximum light utilization coefficient $(\alpha)$ and the light saturation coefficient $\left(E_{k}\right)$ following Eilers and Peeters (1988). In addition, the approximate maximum light use efficiency in the dark-adapted state, the Genty parameter (Genty et al. 1989), was calculated as:

$F_{\mathrm{v}} / F_{\mathrm{m}}=\left(F_{\mathrm{m}}-F_{\mathrm{o}}\right) / F_{\mathrm{m}}$

where $F_{\mathrm{m}}$ is the maximum yield, and $F_{\mathrm{o}}$ is the minimum fluorescence yield in the dark-adapted state. As long periods of dark adaption should be avoided prior to RLCs due to potential modification of the photoacclimation state of the cells investigated (Ralph and Gademann 2005; Perkins et al. 2010) and can be impractical when working under time constraints in situ (Burdett et al. 2012), $F_{\mathrm{v}} / F_{\mathrm{m}}$ was calculated from $F_{\mathrm{m}}$ and $F_{\mathrm{o}}$ values obtained during the initial light curve step of $30 \mathrm{~s}$ darkness. Burdett et al. (2012) demonstrated that a 10-s period was sufficient for the dark adaption of the red coralline alga Lithothamnion glaciale for in situ work, with $\mathrm{F}_{\mathrm{v}} / F_{\mathrm{m}} 95-98 \%$ of the maximum $F_{\mathrm{v}} / F_{\mathrm{m}}$ achieved after 5 min of darkness (=fully darkadapted state). Our methodology thus allowed time constraints to be balanced when working over tidal emersion periods in situ, while allowing for sufficient dark adaptation of samples for RLC techniques (Ralph and Gademann 2005; Burdett et al. 2012).

\section{Data analysis}

All statistical analyses and plotting of data were performed using R v.3.0.2 (R Core Team 2013). Prior to all analyses, normality of data was tested using the Shapiro-Wilk test and examination of frequency histograms. If data were not normally distributed, Box-Cox power transformation was applied using the boxcox function of the MASS package (Venables and Ripley 2002), and normality re-checked. Following the application of models to data as described below, model assumptions were checked by examination of model criticism plots.

\section{Abiotic environment}

Differences in irradiance between seasons (summer and winter) and tidal emersion periods (start, middle and end) were examined for upper shore data, per site, using analysis of variance (ANOVA) with the fixed factors 'Season' (two levels), 'Tide' (three levels) and the interaction term 'Season/Tide'. Post hoc Tukey honest significant differences analysis was performed on significant ANOVA results. Lower shore HB data were analysed as above though with two levels for the factor 'Tide'. Differences in rock pool water temperatures were examined separately per site, using linear mixed-effects models with restricted maximum likelihood (REML) criterion, using the lmer function of package lme4 (Bates et al. 2013). Upper shore data were analysed with the fixed effects 'Season' (two levels), 'Tide' (three levels), the interaction term 'Season/Tide' and 'Pool' as random term (three levels). Lower shore HB data were examined in the same manner though with two levels for the fixed effect 'Tide'. Upper- and lower-bound $P$ values for the ANOVA were calculated for lmer models using the pamer.fnc function of the LMERConvenienceFunctions package (Tremblay and Ransijn 2013). Lower-bound $P$ values (more conservative) and associated denominator degrees of freedom are reported. Post hoc analyses of significant differences highlighted by lmer models were performed using mcposthoc.fnc and summary.mcposthoc 
functions of the same package (Tremblay and Ransijn 2013).

All carbonate chemistry parameters were summarized using principal components analysis (PCA) with scaled variables. Differences in carbonate chemistry between seasons and over tidal emersion periods were examined by analysis of principal component one (PC1) and principal component two (PC2) using linear mixed-effects models as described above. Least squares multiple linear regression was used to examine relationships between PC1 and irradiance (analysed separately as both irradiance measured and calculated cumulative photodose) and rock pool water temperature. The relative importance of predictor variables was calculated using the calc.relimp function of relaimpo package using type 'lmg', whereby $R^{2}$ is partitioned by averaging over orders (Grömping 2006). Only statistically significant regressions are reported.

\section{Photophysiology}

Differences in $\mathrm{rETR}_{\max }, \alpha, E_{k}$ and $F_{\mathrm{v}} / F_{\mathrm{m}}$ were analysed separately per site, using linear mixed-effects models. CM upper shore data were analysed with the fixed effects 'Season' (two levels), 'Tide' (three levels), 'Species' (two levels), interaction terms 'Season/Tide' and 'Species/Tide', and the random term 'Pool' (three levels). HB upper shore data were analysed in the same manner though without the fixed effect 'Species' as only C. officinalis is present. HB lower shore data were analysed in the same manner with the exceptions of two levels for the fixed effect 'Tide'. Calculation of $P$ values and post hoc analyses were conducted as detailed above using the LMERConvenienceFunctions package (Tremblay and Ransijn 2013).

To examine relationships between Corallina spp. and Ellisolandia photophysiology and the prevailing abiotic conditions, $\mathrm{rETR}_{\max }, \alpha, E_{k}$ and $\mathrm{F}_{\mathrm{v}} / F_{\mathrm{m}}$ were regressed against irradiance (separately as both irradiance measured and calculated photodose), rock pool water temperature, PC1 and PC2, using least squares multiple linear regression as detailed above. Only statistically significant regressions are reported.

\section{Results}

\section{Abiotic conditions}

Significantly higher irradiance was recorded during summer than winter at both $\mathrm{CM}\left(F_{1,17}=10.07, P<0.01\right)$ and upper/lower shore $\operatorname{HB}\left(F_{1,17 / 111}=202.37 / 48.74\right.$, $P<0.001$ in both cases) (Fig. 2). Significant differences in irradiance were also apparent over summer tidal emersion at $\mathrm{CM}\left(F_{2,17}=6.78, P<0.05\right)$, and both summer and winter tidal emersion at $\mathrm{HB}\left(F_{2,17}=54.48, P<0.0001\right)$, with significant interaction between 'Season' and 'Tide' $\left(F_{2,17}=6.025, P<0.05\right)$. No significant difference in irradiance was evident between start and end tidal emersion at lower shore HB.

Rock pool water temperatures were significantly higher during summer than winter at $\mathrm{CM}\left(F_{1,17}=2,408.30\right.$, $P<0.0001)$ and upper/lower shore $\mathrm{HB}\left(F_{1,17 / 1,11}=2,9\right.$ $00.70 / 3,927.52, P<0.0001$ in both cases) (Fig. 2). Over tidal emersion periods, no significant difference in water temperature was evident during either summer or winter at $\mathrm{CM}$, while temperatures showed significant increases in both upper $\left(F_{2,17}=67.15, P<0.0001\right)$ and lower shore $\left(F_{1,11}=85.75, P<0.0001\right)$ rock pools at HB during both seasons (Fig. 2). The magnitude of increase in water temperature was greater during summer than winter at $\mathrm{HB}$, as evidenced by significant interaction between 'Season' and 'Tide' for upper $\left(F_{2,17}=21.89, P<0.0001\right)$ and lower shore $\left(F_{1,11}=14.77, P<0.01\right)$ rock pools.

Changes in rock pool water carbonate chemistry were observed over both summer and winter daylight tidal emersion periods at $\mathrm{CM}$ and both upper and lower shore $\mathrm{HB}$ (Figs. 3, 4). $p \mathrm{CO}_{2}$ and $\mathrm{HCO}_{3}{ }^{-}$decreased over tidal emersion, with concomitant increases in $\mathrm{pH}, \mathrm{CO}_{3}{ }^{2-}, \Omega_{\text {arg }}$ and $\Omega_{\mathrm{cal}}$. The greatest magnitude of change in carbonate chemistry was observed over summer tidal emersion in upper shore rock pools at $\mathrm{HB}$, with $p \mathrm{CO}_{2}$ and $\mathrm{HCO}_{3}{ }^{-}$concentrations decreasing to 4 and $25 \%$ of start values, respectively, and $\mathrm{pH}$ increasing to $111 \%$, and $\mathrm{CO}_{3}{ }^{2-}, \Omega_{\text {arg }}$ and $\Omega_{\text {cal }}$ all increasing to ca. $220 \%$ of start values, by the end of tidal emersion.

PCA served to summarize all carbonate chemistry parameters for subsequent analysis (Table 2; Fig. 5). PC1 described $89.3 \%$ of the variance in carbonate chemistry data and represented changes in rock pool carbonate chemistry observed over tidal emersion periods, i.e. a shift from high $p \mathrm{CO}_{2}, \mathrm{HCO}_{3}{ }^{-}$and high overall DIC, to high $\mathrm{pH}, \mathrm{CO}_{3}{ }^{2-}, \Omega_{\text {arg }}$ and $\Omega_{\text {cal }}$ (Table 2; Fig. 5). PC2 accounted for $8.2 \%$ of the variance and, mainly, represented differences in TA within the data (Table 2; Fig. 5). Significantly higher values of PC1 were observed for summer data than winter data for $\mathrm{CM}\left(F_{1,32}=94.92, P<0.0001\right)$, and upper $\left(F_{1,32}=767.30, P<0.0001\right)$ and lower shore $\mathrm{HB}$ $\left(F_{1,20}=165.14, P<0.0001\right)$ (Fig. 6$)$. PC1 also showed significant increases over tidal emersion periods during both summer and winter for $\mathrm{CM}\left(F_{2,32}=22.18, P<0.0001\right)$, and upper $\left(F_{2,32}=345.72, P<0.0001\right)$ and lower shore HB $\left(F_{1,20}=119.35, P<0.0001\right)$ (Fig. 6$)$. The magnitude of increase in $\mathrm{PC} 1$ was greater during summer than winter for HB upper shore, as shown by significant interaction between 'Season' and 'Tide' $\left(F_{2,32}=9.38, P<0.0001\right)$.

PC2, mainly representing TA within the dataset, was not significantly different between seasons for CM or upper 

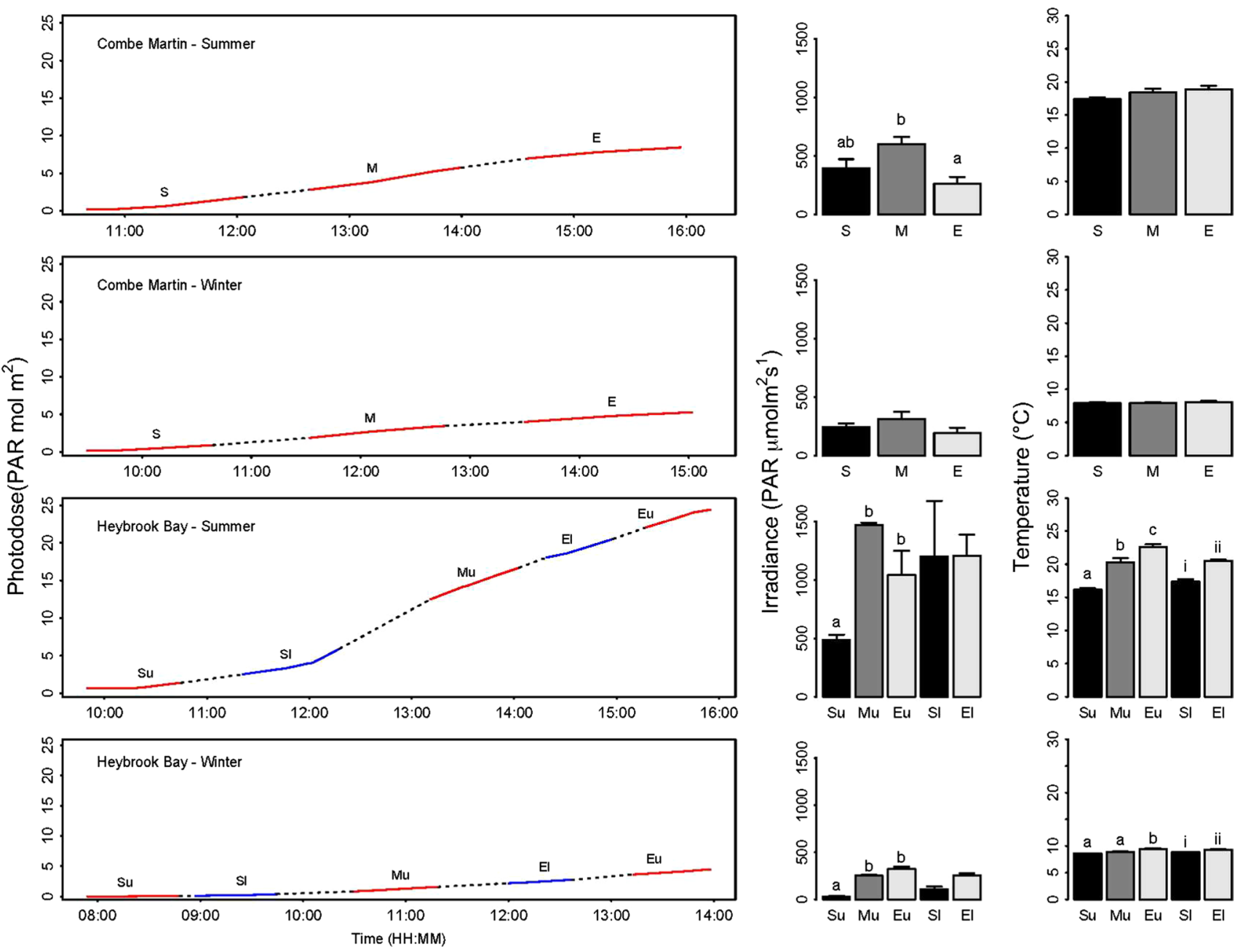

Fig. 2 Photodose, irradiance and rock pool water temperature over summer and winter tidal emersion periods at $\mathrm{CM}$ and $\mathrm{HB}$. Large plots display photodose as a function of time, with start $(S)$, middle $(M)$ and end $(E)$ sampling times highlighted in red for $\mathrm{CM}$ and start $(\mathrm{Su})$, middle $(M u)$ and end $(E u)$ upper shore sampling times highlighted

shore HB, though it was significantly different between summer and winter for lower shore $\operatorname{HB}\left(F_{1,20}=15.64\right.$, $P<0.01$ ) (Fig. 7). Over tidal emersion periods, PC2 significantly decreased for CM upper shore during both summer and winter $\left(F_{2,32}=28.37, P<0.0001\right)$. PC2 was also significantly different between start and end lower shore HB tidal emersion $\left(F_{1,20}=15.61, P<0.01\right)$, with the direction of change different during summer and winter, as highlighted by significant interaction between 'Season' and 'Tide' $\left(F_{1,20}=92.03, P<0.0001\right)$. While no significant difference in PC2 was observed for HB in relation to 'Tide', there was a significant interaction between 'Season' and 'Tide' $\left(F_{2,32}=3.85, P<0.05\right)$.

Least squares multiple linear regression identified significant relationships between carbonate chemistry (as PC1) in relation to photodose and rock pool water temperature in red for HB. Start $(S l)$ and end $(E l)$ lower shore sampling times at $\mathrm{HB}$ are indicted in blue. Middle and right columns represent average $(n=9 \pm \mathrm{SE})$ irradiance and water temperature at the start, mid and end tidal emersion, respectively. Letters and numerals denote significant differences for upper and lower shore, respectively

$\left(R^{2}=0.82, P<0.0001\right)$ (Table 3; Fig. 8). The relative importance of predictors was given as $67 \%$ for photodose and $32 \%$ for temperature, respectively.

\section{Corallina and Ellisolandia photophysiology}

Corallina officinalis, C. caespitosa and E. elongata all demonstrated significantly higher $\mathrm{rETR}_{\max }$ and $E_{k}$ during winter as compared to summer (Table 4; Figs. 9, 10). $F_{\mathrm{v}} / F_{\mathrm{m}}$ recorded at the middle and end of tidal emersion at CM was significantly different between seasons for both $C$. officinalis and $C$. caespitosa (post hoc Tukey, $P<0.05$ ), while no significant difference in $\alpha$ was observed for any species in relation to 'Season'.

Over tidal emersion periods, significant changes in photophysiology parameters were observed at both CM and HB 

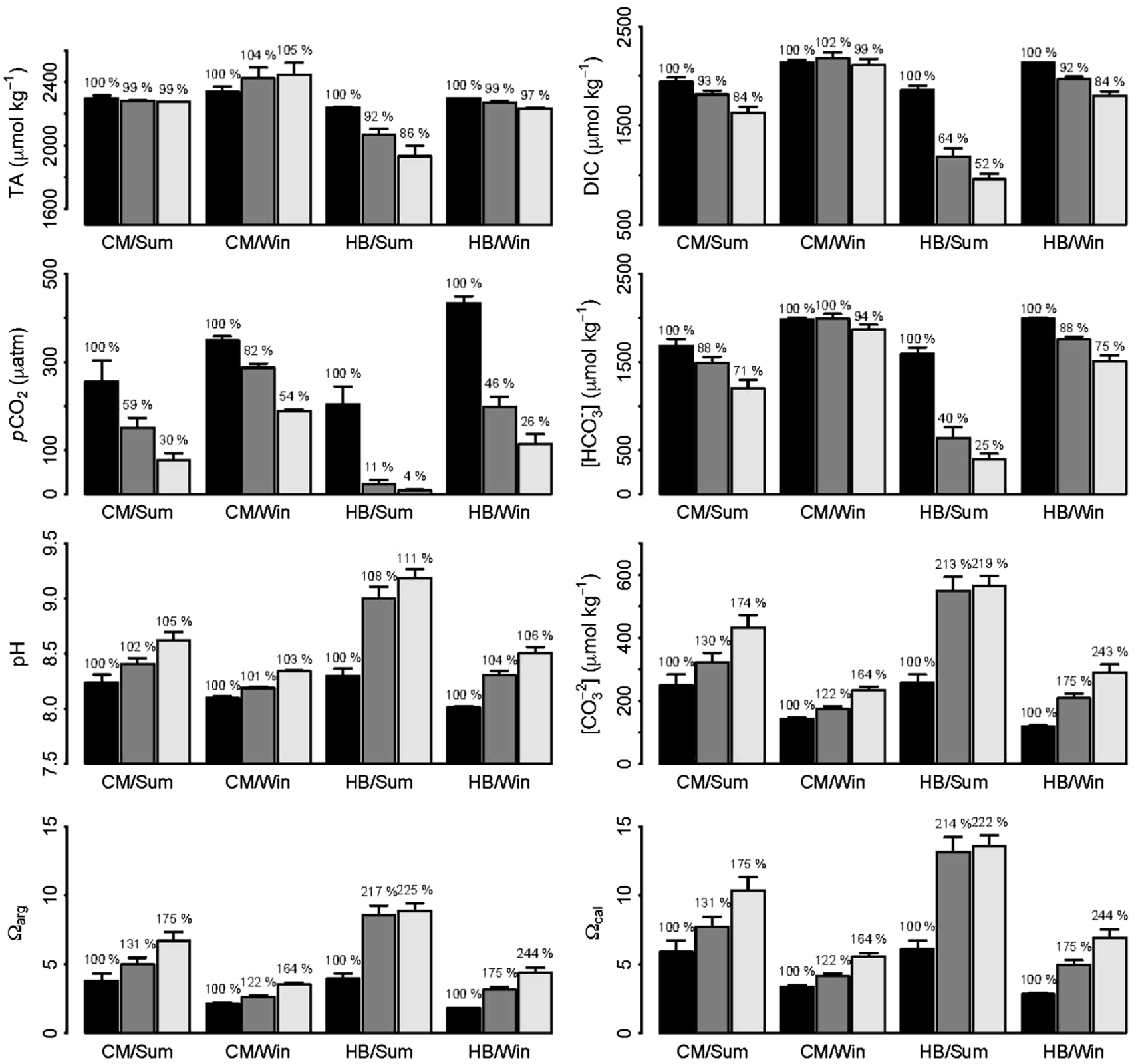

Fig. 3 Average carbonate chemistry (TA, DIC, $p \mathrm{CO}_{2}, \mathrm{HCO}_{3}{ }^{-}, \mathrm{pH}$, $\mathrm{CO}_{3}{ }^{2-}, \Omega_{\text {arg }}$ and $\Omega_{\text {cal }}$ ) recorded during summer (Sum) and winter (Win) at upper shore Combe Martin $(C M)$ and Heybrook Bay $(H B)$,

at the start (black bars), middle (dark grey bars) and end (light grey bars) of tidal emersion periods ( $n=6 \pm$ SE). Percentages denote $\%$ change in parameters in relation to start values

upper/lower shore (Table 4; Figs. 9, 10). At CM, C. officinalis and $C$. caespitosa $\mathrm{rETR}_{\max }$ and $\alpha$ demonstrated divergent trends over tidal emersion between seasons, supported by significant interaction between 'Season' and 'Tide'. During summer, both species' rETR $_{\max }$ rose gradually over tidal emersion at $\mathrm{CM}$, though significant increases were restricted to $C$. caespitosa. Concomitantly, $\alpha$ increased, showing significantly higher values at the end of emersion, with significantly decreased $E_{k}$. C. officinalis $\mathrm{F}_{\mathrm{v}} / F_{\mathrm{m}}$ decreased at mid emersion, but recovered by end emersion, with $C$. caespitosa $F_{\mathrm{v}} / F_{\mathrm{m}}$ also showing significant increase. During winter,

C. officinalis and C. caespitosa photophysiology showed almost identical trends. rETR $_{\text {max }}$ decreased from start to mid emersion, showing recovery by end emersion; $\alpha$ and $F_{\mathrm{v}} / F_{\mathrm{m}}$ were significantly decreased at mid emersion in comparison with start and end; and $E_{k}$ was significantly increased at mid emersion. No significant difference in $\mathrm{rETR}_{\max }, \alpha$ or $E_{k}$ was observed between $C$. officinalis and $C$. caespitosa during summer or winter tidal emersion, while $C$. officinalis $F_{\mathrm{v}} / F_{\mathrm{m}}$ was significantly increased at the start of tidal emersion during both summer and winter in comparison with $C$. caespitosa (post hoc Tukey, $P<0.05$ ). 

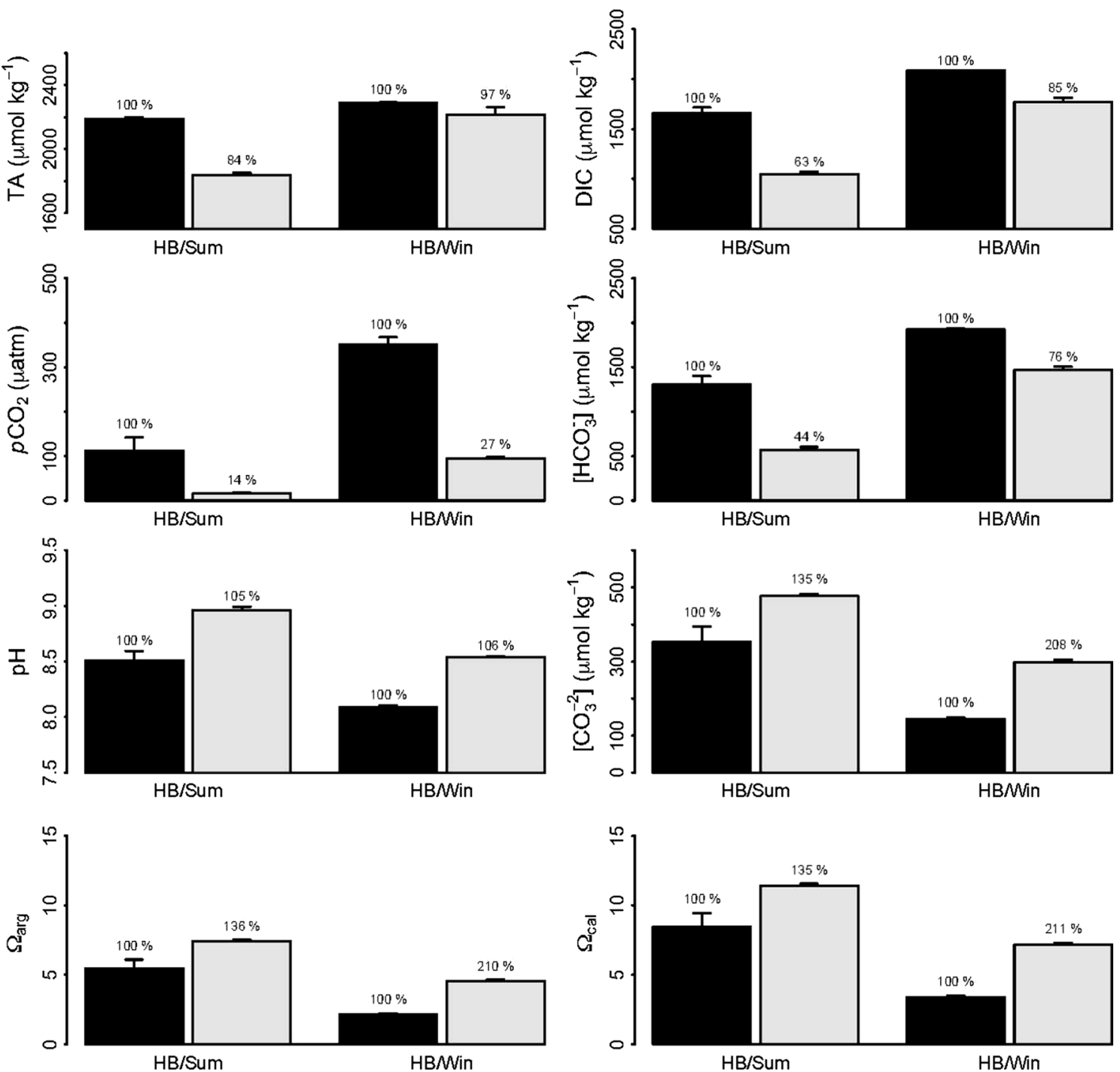

Fig. 4 Average carbonate chemistry (TA, DIC, $p \mathrm{CO}_{2}, \mathrm{HCO}_{3}{ }^{-}, \mathrm{pH}$, $\mathrm{CO}_{3}{ }^{2-}, \Omega_{\text {arg }}$ and $\Omega_{\text {cal }}$ ) recorded during summer (Sum) and winter (Win) at lower shore Hebrook Bay $(H B)$, at the start (black bars) and

end (light grey bars) of tidal emersion periods ( $n=6 \pm$ SE). Percentages denote $\%$ change in parameters in relation to start values

In upper shore rock pools of $\mathrm{HB}, C$. officinalis $\mathrm{rETR}_{\max }$ demonstrated the opposite trend to that observed during summer at CM, decreasing significantly to $41 \%$ of initial values by the end of tidal emersion. $\alpha$ showed no significant change over emersion, while $E_{k}$ also demonstrated a significant decrease to $55 \%$ of start values. Decreases in $F_{\mathrm{v}} / F_{\mathrm{m}}$ observed from start to mid emersion showed recovery, though this was not statistically significant. $\mathrm{rETR}_{\max }$ also decreased over winter tidal emersion, though to a lessor extent than during summer (73\% of start values), accompanied by decreases in $\alpha$ and $F_{\mathrm{v}} / F_{\mathrm{m}}$ and increases in $E_{k}$. The magnitude of decrease in $F_{\mathrm{v}} / F_{\mathrm{m}}$ was greater during winter and the direction of change in $E_{k}$ different between seasons, as highlighted by significant interaction between 'Season' and 'Tide'.

No significant difference in any photophysiology parameter was apparent for $C$. officinalis over summer tidal emersion at lower shore $\mathrm{HB}$, with E. elongata only showing decreased $E_{k}$ from start to end emersion (Table 4; Fig. 10). During winter, significant decrease in $C$. officinalis rETR $_{\text {max }}$ was evident from start to end emersion, accompanied by decrease in $\alpha$ and $F_{\mathrm{v}} / F_{\mathrm{m}}$. Conversely, E. elongata demonstrated no significant change in any parameter. There was no significant difference between $C$. officinalis and $E$. elongata photophysiology at lower shore HB during either season over tidal emersion, though significant interaction between 'Species' and 'Tide' was apparent.

Corallina and Ellisolandia HETR $_{\max }$ showed a significant negative linear relationship $\left(R^{2}=0.65, P<0.001\right.$, $n=70$ ) with irradiance (as measured) (37\% relative 
Table 2 Component loadings of principal components analysis of carbonate chemistry parameters (TA, DIC, $\mathrm{pH}, p \mathrm{CO}_{2}, \mathrm{HCO}_{3}{ }^{-}, \mathrm{CO}_{3}{ }^{2-}, \Omega_{\mathrm{arg}}$ and $\Omega_{\text {cal }}$ )

\begin{tabular}{|c|c|c|c|}
\hline & $\mathrm{PC} 1(\%)$ & PC2 (\%) & PC3 $(\%)$ \\
\hline Proportion of variance & 89.3 & 8.2 & 2.0 \\
\hline Cumulative proportion & 89.3 & 97.5 & 99.5 \\
\hline Variable & $\mathrm{PC} 1$ & $\mathrm{PC} 2$ & PC3 \\
\hline \multicolumn{4}{|l|}{ Component loadings } \\
\hline TA & -0.27 & -0.81 & 0.12 \\
\hline DIC & -0.36 & -0.27 & -0.11 \\
\hline $\mathrm{pH}$ & 0.36 & -0.09 & 0.01 \\
\hline$p \mathrm{CO}_{2}$ & -0.34 & 0.23 & 0.89 \\
\hline $\mathrm{HCO}_{3}^{-}$ & -0.37 & -0.13 & -0.15 \\
\hline $\mathrm{CO}_{3}{ }^{2-}$ & 0.36 & -0.24 & 0.20 \\
\hline$\Omega_{\text {arg }}$ & 0.36 & -0.23 & 0.23 \\
\hline$\Omega_{\mathrm{cal}}$ & 0.36 & -0.24 & 0.21 \\
\hline
\end{tabular}

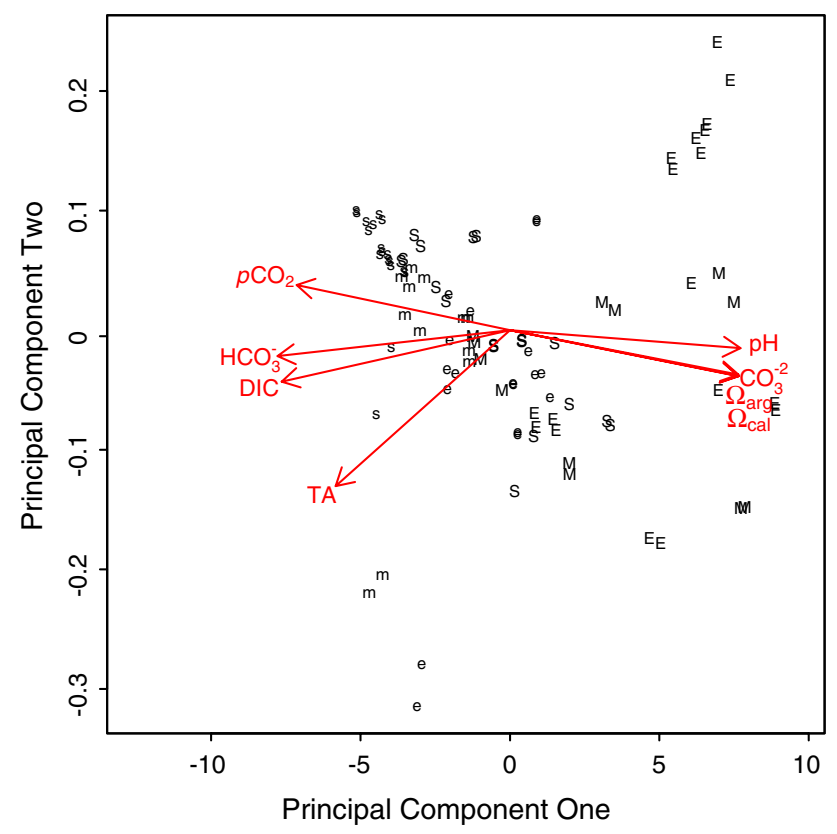

Fig. 5 Principal components analysis of carbonate chemistry parameters, showing principal component one ( $89.3 \%$ of variance) in relation to principal component two $(8.2 \%$ of variance). Summer data are indicated by upper case letters and winter by lower case letters, representing the start $(s)$, mid $(m)$ and end $(e)$ of tidal emersion periods

importance) and water temperature (45\% relative importance) (Table 5; Fig. 11). PC1 (16\% relative importance) and PC2 (0\% relative importance) were included in this regression to represent carbonate chemistry, though nonsignificant coefficients were returned for these predictors (Table 5); removal of these predictors did not improve the model quality.

\section{Discussion}

Recent insights into the identity and distribution of NE Atlantic Corallina and Ellisolandia allow for updated assessment of species' ecology underpinned by clear species concepts (Williamson et al. in review, 2009; Brodie et al. 2013). This study represents the first documentation of $C$. caespitosa, as distinguished from $C$. officinalis, photophysiology and contributes to our general understanding of geniculate coralline algal photophysiology in relation to prevailing abiotic conditions. PAM fluorescence and the application of RLC techniques (Ralph and Gademann 2005; Perkins et al. 2006; Burdett et al. 2012) permitted the non-destructive assessment of actual, as opposed to optimal, photosynthetic state of Corallina and Ellisolandia over summer and winter tidal emersion, facilitating comparison to prevailing irradiance, water temperature and carbonate chemistry conditions. This information is pertinent as research attempts to predict the potential impacts of climate change and OA on calcifying macroalgal species (Harley et al. 2012).

Abiotic conditions

Our data highlight that Corallina and Ellisolandia species inhabiting intertidal rock pools are exposed to highly fluctuating irradiance, temperature and carbonate chemistry conditions over both long-term seasonal and short-term tidal emersion periods (Figs. 2, 3, 4, 6). These findings are consistent with previously reported accounts of rock pool habitats (e.g. Ganning 1971; Daniel and Boyden 1975; Truchot and Duhamel-Jouve 1980; Morris and Taylor 1983). Irradiance and temperature increased and were comparatively variable over summer emersion, with irradiance 


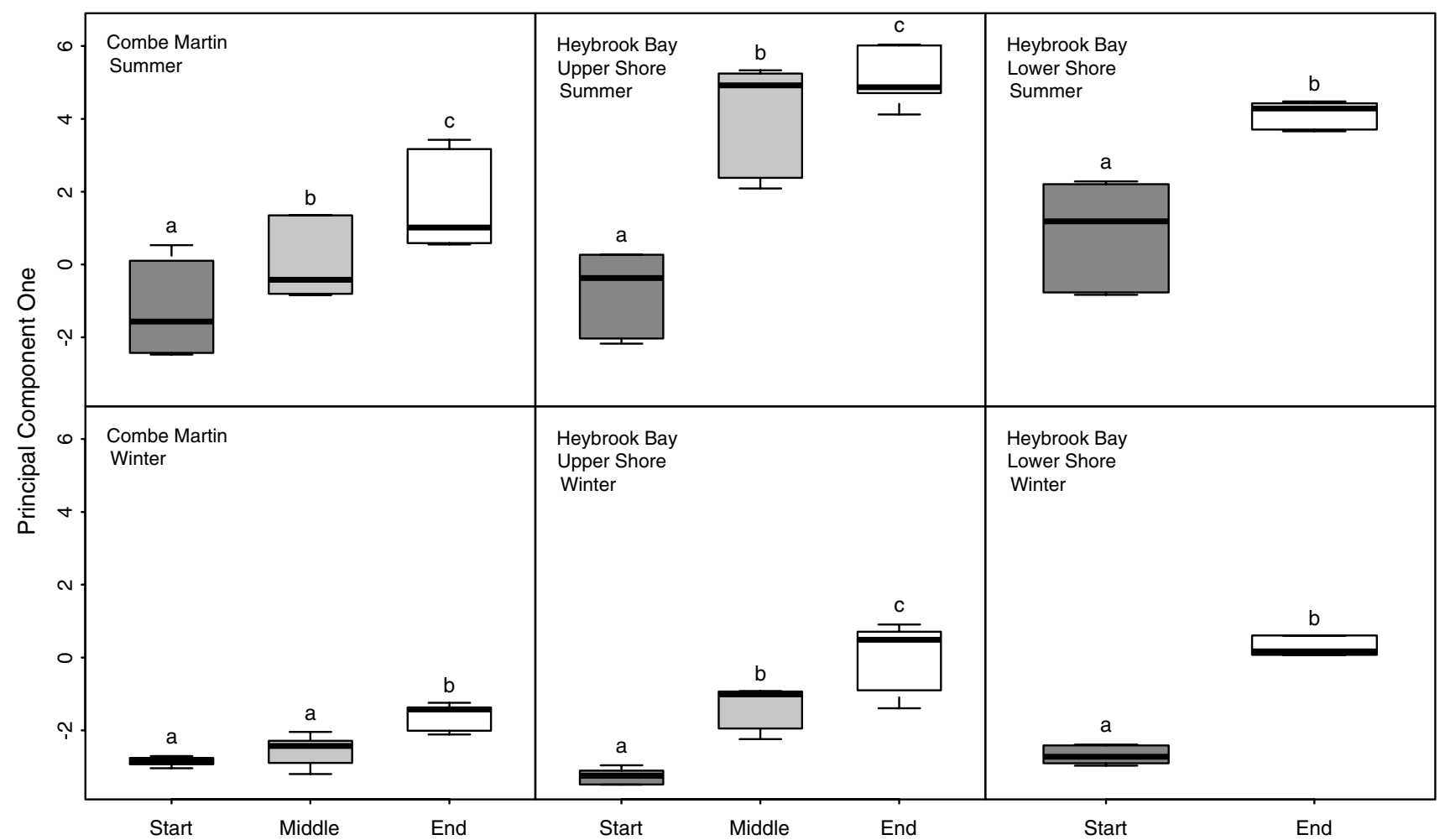

Fig. 6 Boxplots showing the median, minimum, maximum and first and third quartiles of principal component one in relation to tidal emersion period at upper shore Combe Martin and upper and lower shore Heybrook bay. Letters denote significant difference

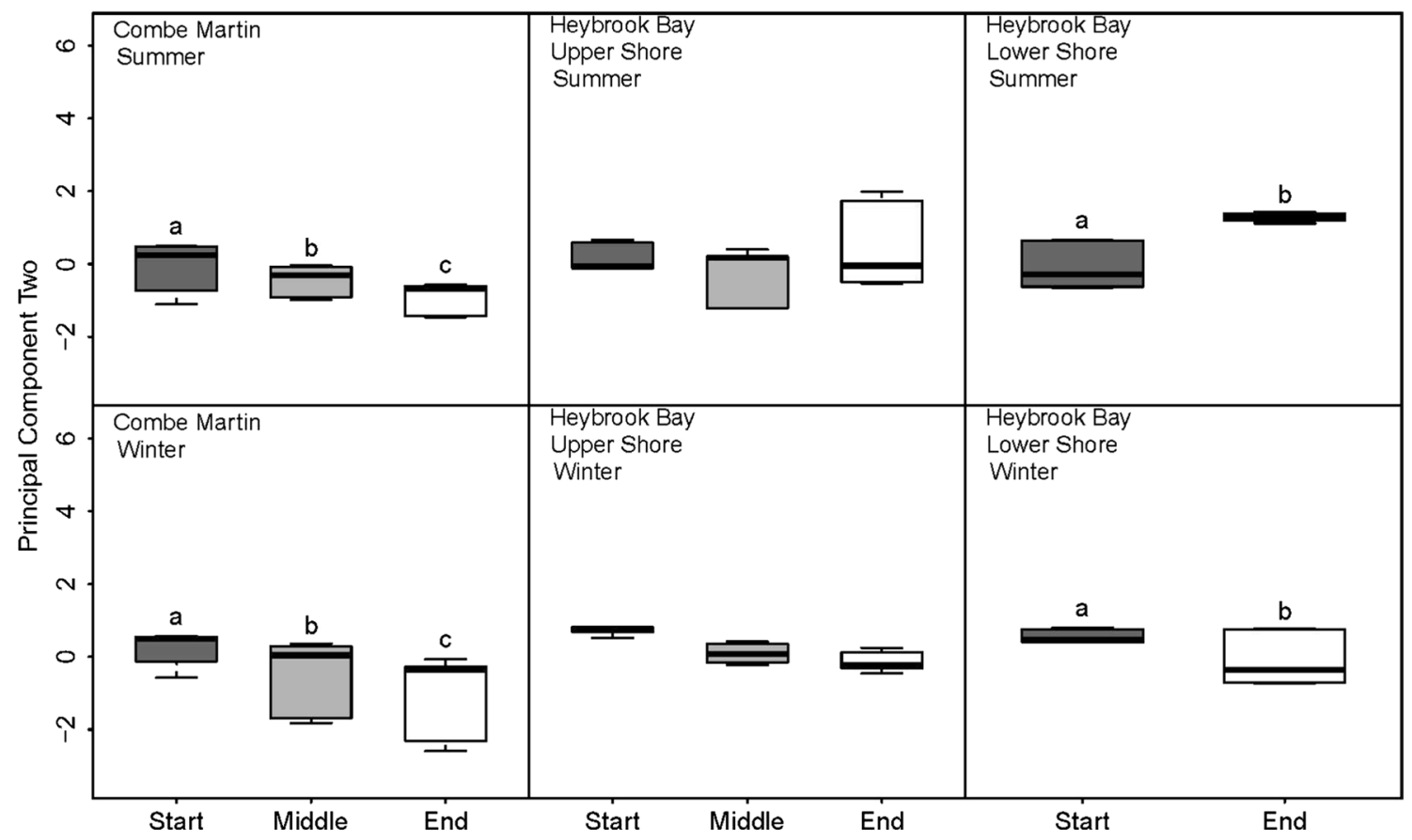

Fig. 7 Boxplots showing the median, minimum, maximum and first and third quartiles of principal component two in relation to tidal emersion period at upper shore Combe Martin and upper and lower shore Heybrook bay. Letters denote significant difference 
Table 3 Multiple linear regression analysis of principal component one (PC1) in relation to irradiance (as cumulative photodose) and rock pool water temperature (Temp.), showing associated standard error (SE) of coefficients, the significance of predictor variables within the model (Pred. sig.), the relative importance of predictor variables (Rel. imp.), associated overall model $R^{2}$ and significance (Model $P$ ), and the number of observations $(n)$

\begin{tabular}{|c|c|c|c|c|c|c|c|c|c|c|}
\hline \multirow[t]{2}{*}{ Relationship $\left(Y=a+b_{1} * X_{1}+b_{2} * X_{2}\right)$} & \multicolumn{3}{|c|}{ Coefficient SE } & \multicolumn{2}{|l|}{ Pred. sig. } & \multicolumn{2}{|c|}{ Rel. imp. } & \multirow[t]{2}{*}{$R^{2}$} & \multirow[t]{2}{*}{ Model $P$} & \multirow[t]{2}{*}{$n$} \\
\hline & $a$ & $b_{1}$ & $b_{2}$ & $X_{1}$ & $X_{2}$ & $X_{1}$ & $X_{2}$ & & & \\
\hline $\mathrm{PC} 1=-3.456+0.270$ Photodose +0.134 Temp & 0.321 & 0.019 & 0.025 & $<0.0001$ & $<0.0001$ & $67 \%$ & $32 \%$ & 0.83 & $<0.0001$ & 96 \\
\hline
\end{tabular}

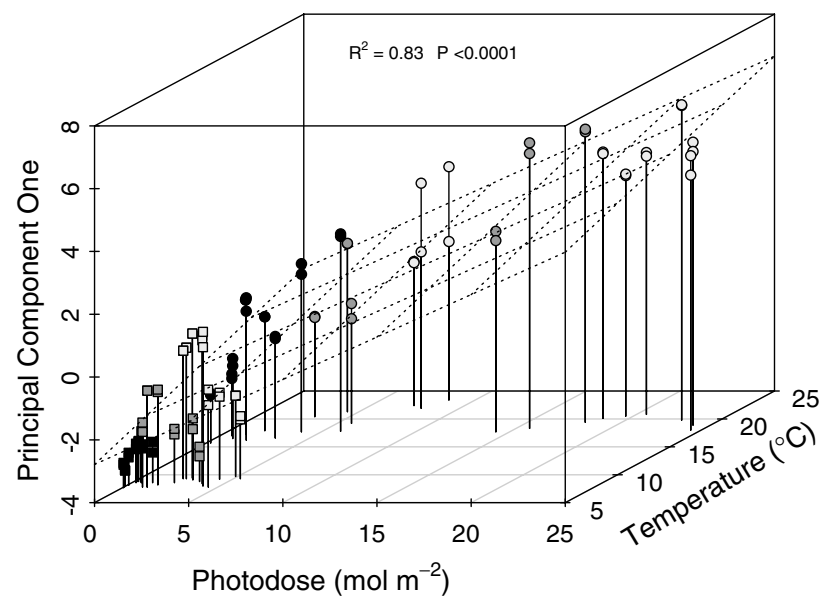

Fig. 8 Multiple linear regression of principal component one in relation to photodose (67\% relative importance) and rock pool water temperature (32\% relative importance). Dashed grid demonstrates the regression plane. Summer (circles) and winter (squares) data are highlighted in relation to start (black), middle (dark grey) and end (light grey) tidal emersion

ranging from ca. 487-1,467 $\mu \mathrm{mol}$ photons $\mathrm{m}^{-2} \mathrm{~s}^{-1}$ at $\mathrm{HB}$, with a concomitant increase of ca. $6.4{ }^{\circ} \mathrm{C}$ in rock pool temperatures. Lack of significant increase in water temperature over summer or winter tidal emersion at $\mathrm{CM}$ was likely due to the larger volumes of rock pools examined at this site (Table 1). Given that smaller and shallower rock pools experience more extreme environmental conditions (Ganning 1971), more stressful conditions may be predicted within upper shore rock pools at HB in comparison with CM. At lower shore HB, rock pool water temperature increases over emersion periods were smaller in magnitude than observed in upper shore pools, consistent with the shorter duration of tidal emersion experienced at lower shore and known gradients of stress experienced across the intertidal (Ganning 1971; Martins et al. 2007).

Significant fluctuations in rock pool carbonate chemistry recorded during the present study were explainable to a high degree $\left(R^{2}=0.82\right)$ by photodose and rock pool water temperature (Figs. 3, 4, 8). These findings are similar to a recent study that demonstrated prediction of DIC fluctuations in a macrophyte meadow using a simple statistical model comprised of three parameters: wind speed, wind direction and PAR (Saderne et al. 2013). Of our two predictors, photodose showed the strongest relative importance in explaining carbonate chemistry dynamics $(67 \%$ as compared to $32 \%$ for temperature) which is understandable given the cumulative nature of change in carbonate chemistry over tidal emersion, and the driving role of irradiance for photosynthesis and thus inorganic carbon utilization in rock pools (Truchot and Duhamel-Jouve 1980; Morris and Taylor 1983). Temperature may influence carbonate chemistry both through indirect effects to rock pool inhabitant metabolic rates (Morris and Taylor 1983) and by direct effects to the solubility of $\mathrm{CO}_{2}$ in seawater (Wootton et al. 2008).

While Corallina and Ellisolandia photophysiology did not demonstrate significant relationships with carbonate chemistry across our data, carbonate chemistry dynamics highlighted by this work are important when considering their potential response's to future OA. As OA proceeds, periodic exposure to high $\mathrm{pH}$ conditions may ameliorate some of the negative impacts of OA for calcifying species (Hurd et al. 2011; Anthony et al. 2011; Manzello et al. 2012). In addition, exposure to natural $\mathrm{pH}$ variability has been linked to increased resilience of calcifying species to future OA conditions (Wootton et al. 2008; Hofmann et al. 2011; Kelly et al. 2013; Wolfe et al. 2013). Mixed responses of $C$. officinalis and E. elongata to future OA conditions have been demonstrated to-date by incubation studies employing static $\mathrm{pH}$ conditions (Hofmann et al. 2012, 2013; Noisette et al. 2013; Egilsdottir et al. 2013). To fully elucidate OA impacts to intertidal geniculate coralline species, incubation experiments should be conducted that incorporate natural variability in carbonate chemistry experienced in situ during both daylight and night-time tidal emersion; the latter of which results in opposite trends in carbonate chemistry to those described here (Truchot and Duhamel-Jouve 1980; Egilsdottir et al. 2013).

Photophysiology

Corallina and Ellisolandia photophysiology demonstrated patterns of both long-term, seasonal acclimation to changing irradiance and temperature and short-term (hours) acclimation to irradiance changes over tidal emersion 
Table 4 Analysis of variance of Corallina and Ellisolandia photophysiology $\left(\mathrm{rETR}_{\max }, \alpha, E_{k}\right.$ and $\left.F_{\mathrm{v}} / F_{\mathrm{m}}\right)$ in relation to season, tide and species

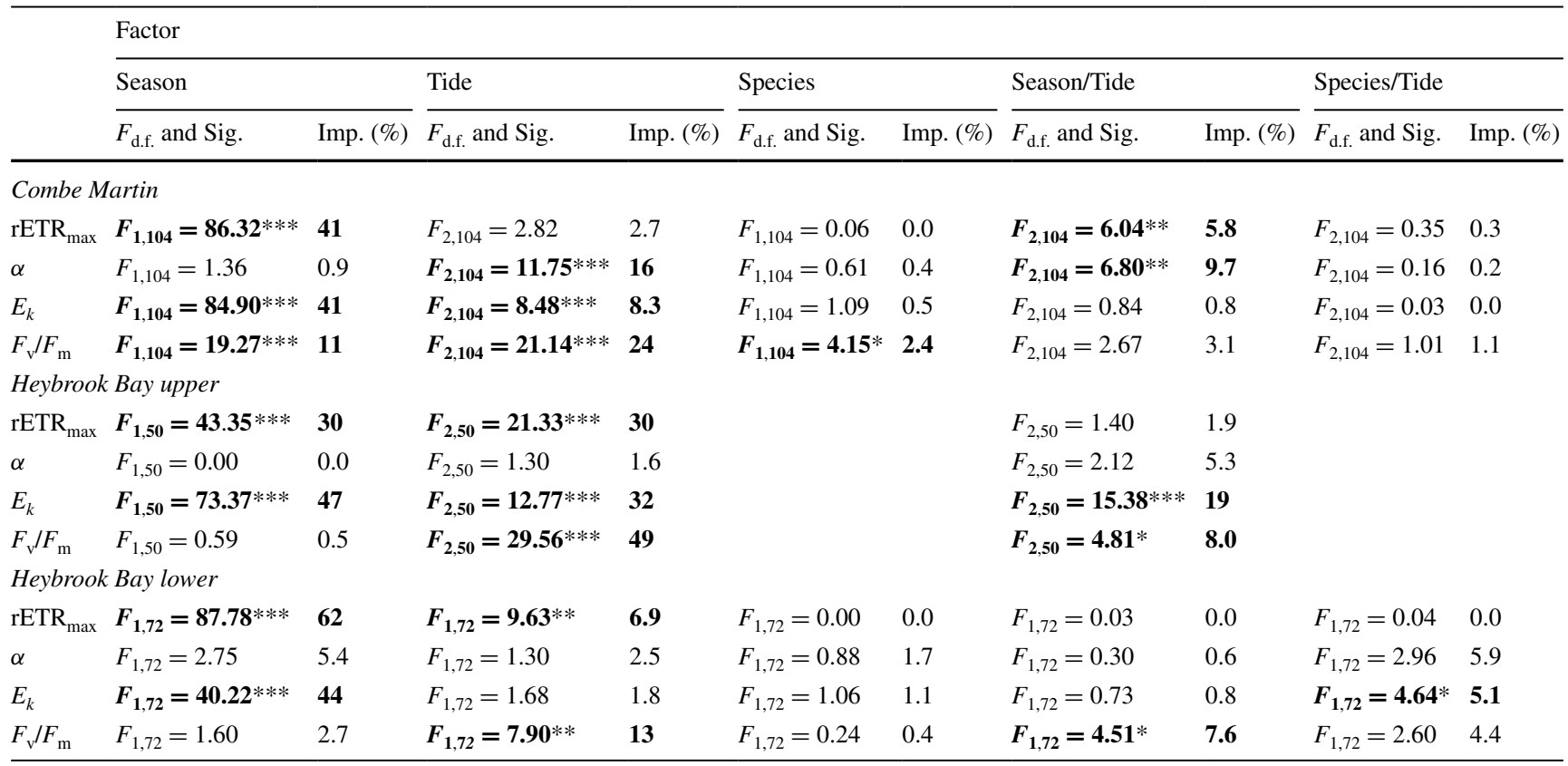

$F$ ratios, degrees of freedom and associated significance $\left(F_{\text {d.f. }}\right.$ and Sig.) $(* * * P<0.001 ; * * P<0.01 ; * P<0.05)$, and the relative importance of fixed effects (Imp.) are displayed, as determined from linear mixed-effects models. Significant differences are highlighted in bold

during the present study, with the efficiency of short-term acclimation seemingly dependent on the seasonal state. At the seasonal resolution, significantly lower $\mathrm{rETR}_{\max }$ and $E_{k}$ were observed for C. officinalis, C. caespitosa and E. elongata during summer, with a negative relationship identified between $\mathrm{rETR}_{\max }$ and irradiance and temperature across all data (Fig. 11). For most intertidal macroalgae, the quantity of PAR impinging on a plant during summer is often far in excess of that needed to saturate photosynthesis (Franklin and Forster 1997). Excess irradiance can lead to photooxidative damage via increased production of reactive oxygen species, and, in extreme cases, this can cause pigment bleaching and death (Muller et al. 2001). As such, macroalgae must acclimate to changes in light intensity in a manner that optimizes photosynthesis and growth, while controlling for potential stress. Long-term acclimation to changes in light intensity can be achieved via regulation of the size of light-harvesting pigment antennae, through changes in gene expression and proteolysis (Muller et al. 2001).

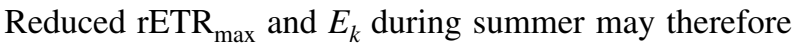
reflect seasonal acclimation of Corallina and Ellisolandia photochemistry as a seasonal response to excess summer irradiance. In this respect, the reverse acclimation to low light conditions must be performed in winter to allow efficient harvesting of reduced irradiance levels. As significantly higher values of rETR $_{\max }$ were observed for all species during winter, when minimal irradiance was observed, our data indicate that Corallina and Ellisolandia are more effective at harvesting and utilizing light energy at low fluence rates, as proposed by Häder et al. (1997) and Häder et al. (2003), who described geniculate coralline species as typical 'shade plants'.

Over summer tidal emersion at CM, diurnal patterns observed in Corallina photophysiology were suggestive of the ability to rapidly acclimate photochemistry to significant changes in irradiance experienced. $C$. officinalis and C. caespitosa demonstrated diurnal patterns in $F_{\mathrm{v}} / F_{\mathrm{m}}$ indicative of photosynthetic downregulation by dynamic photoinhibition, the dissipation of excess light energy as heat (Franklin and Forster 1997). This can serve to prevent longlasting photooxidative damage caused by excess irradiance, while allowing maintenance of photosynthetic rates (Davison and Pearson 1996; Franklin and Forster 1997; Muller et al. 2001). From start to mid summer emersion, $F_{\mathrm{v}} / F_{\mathrm{m}}$ decreased or remained reduced when increases in irradiance were observed, followed by complete recovery at the end of emersion when irradiance decreased. Concomitantly, C. officinalis and C. caespitosa $\mathrm{rETR}_{\max }$ was maintained and increased, respectively. This confirms that $C$. officinalis and $C$. caespitosa possess the ability to rapidly down-regulate photochemistry in response to excess irradiance over summer tidal emersion, while maintaining electron transport rates. It further demonstrates that down regulation is a dynamic process in these species, easily reversible during summer over the duration of tidal emersion.

Significant decreases in HB upper shore $C$. officinalis rETR $_{\max }$ and $E_{k}$ over summer tidal emersion, however, did not follow the same trend as observed at CM and may 


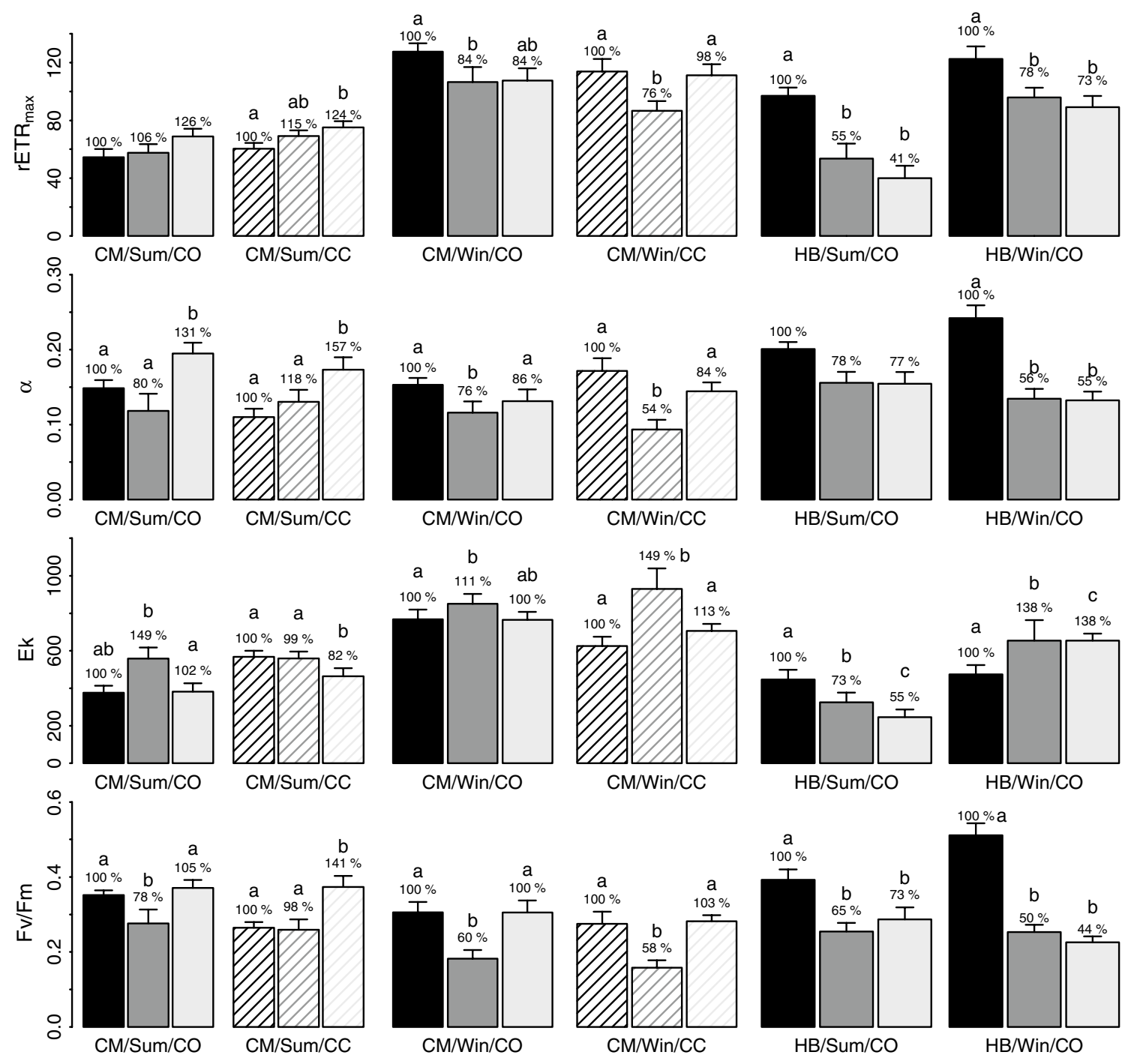

Fig. 9 Average Corallina officinalis ( $\mathrm{CO}$-filled bars), and Corallina caespitosa $\left(C C\right.$-lined bars) $\mathrm{rETR}_{\max }, \alpha, E_{k}$ and $F_{\mathrm{v}} / F_{\mathrm{m}}$ at upper shore Combe Martin $(C M)$ and Heybrook Bay (HB) at the start (black bars), middle (dark grey bars) and end (light grey bars) of summer

(Sum) and winter (Win) tidal emersion periods ( $n=9 \pm$ SE). Percentages demonstrate \% change in parameters normalized to start emersion values. Letters denote significant differences

indicate electron transport limitation by high $\mathrm{pH} /$ low inorganic carbon conditions. While photoinhibition was evident in response to the relatively extreme irradiance prevailing, as evidenced by decreases in $F_{\mathrm{v}} / F_{\mathrm{m}}$, these decreases were not proportional to $\mathrm{rETR}_{\max }$ reduction and showed signs of recovery at end emersion, while $\mathrm{rETR}_{\max }$ did not. Continual decrease in ETR has been observed for $U$. intestinalis, F. vesiculosus and Chondrus crispus across simulated tidal emersion periods in artificial rock pools, due to parallel increases in $\mathrm{pH}$ and decreases in inorganic carbon concentrations (Björk et al. 2004). With the depletion of $p \mathrm{CO}_{2}$, algae become dependent on $\mathrm{HCO}_{3}{ }^{-}$utilization, via conversion to $\mathrm{CO}_{2}$ either by extracellular CA (Invers et al. 1997; Badger 2003), or by direct anion exchange-mediated uptake (Larsson and Axelsson 1999). At high pH (8.459.3), macroalgal CA activity is often ineffective (Middelboe and Hansen 2007a, b), with consequent decreases in photosynthetic rates $(41-78 \%)$ reported for several macroalgal species, compared to rates measured at lower $\mathrm{pH}$ (8-8.1) (Israel and Hophy 2002; Middelboe and Hansen 2007a, b; Semesi et al. 2009). While carbonate chemistry changes did not show significant regression to $\mathrm{rETR}_{\max }$ across all data during the present study, extremes in $\mathrm{pH}$ (average $\mathrm{pH} 9.18 \pm 0.08$ ) and, significantly reduced $p \mathrm{CO}_{2}$ $(-96 \%)$ and $\mathrm{HCO}_{3}{ }^{-}(-75 \%)$ concentrations apparent in upper shore HB rock pools at the end of summer emersion, may have contributed to decreases in C. officinalis $\mathrm{rETR}_{\max }$ and warrant further investigation. 

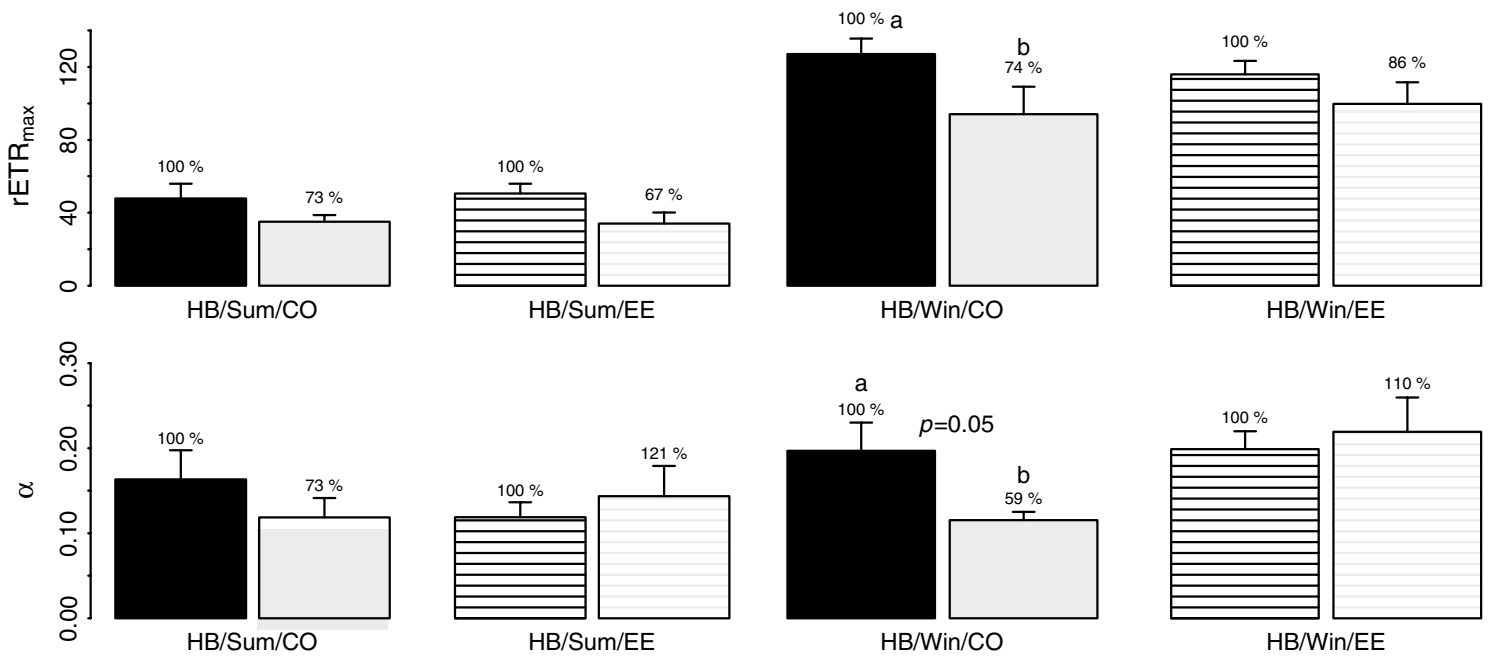

$\mathrm{HB} / \mathrm{Sum} / \mathrm{EE}$

$\mathrm{HB} / \mathrm{Win} / \mathrm{CO}$

HB/Win/EE
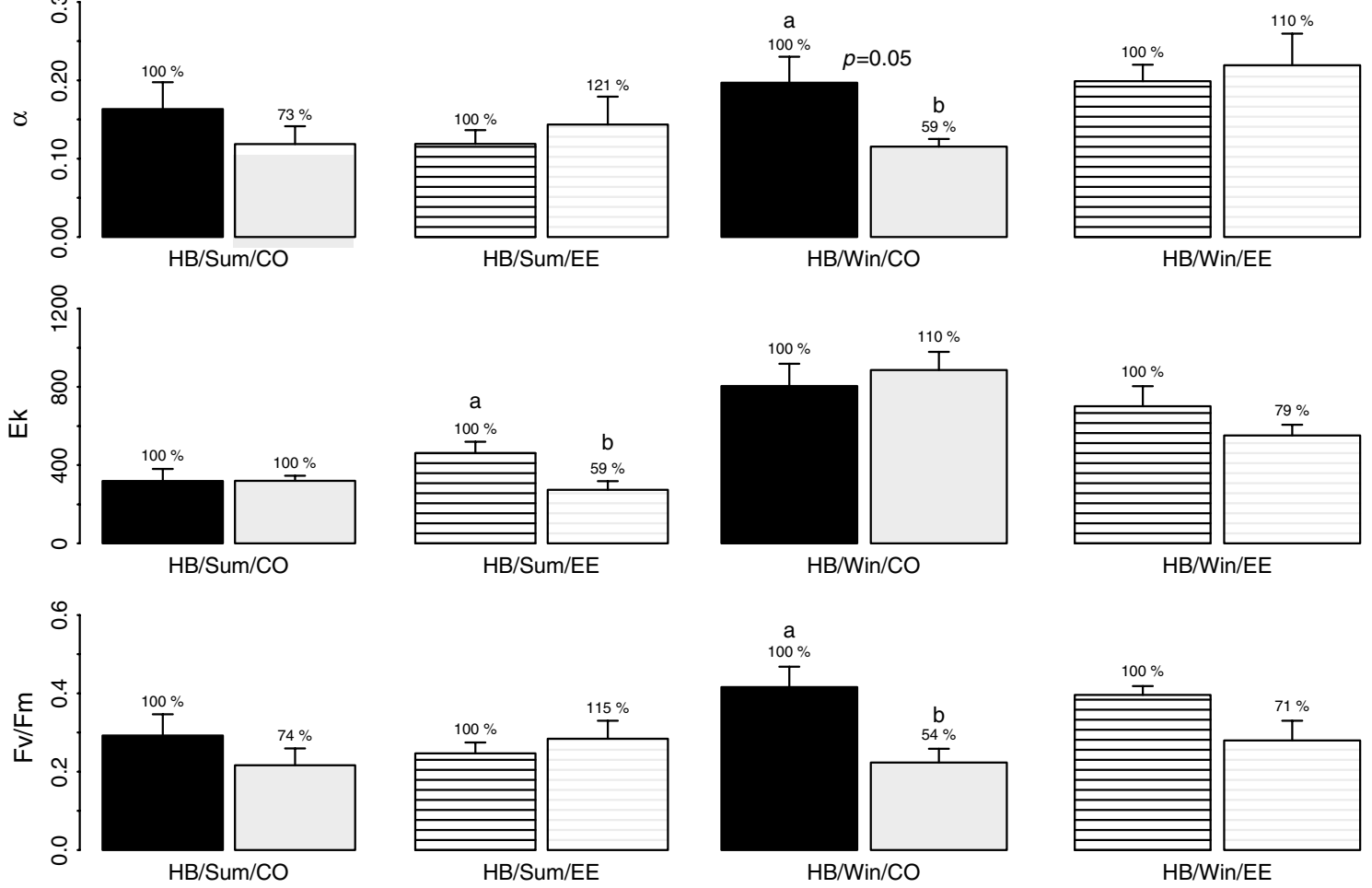

$\mathrm{HB} / \mathrm{Win} / \mathrm{CO}$

$\mathrm{HB} /$ Win/EE
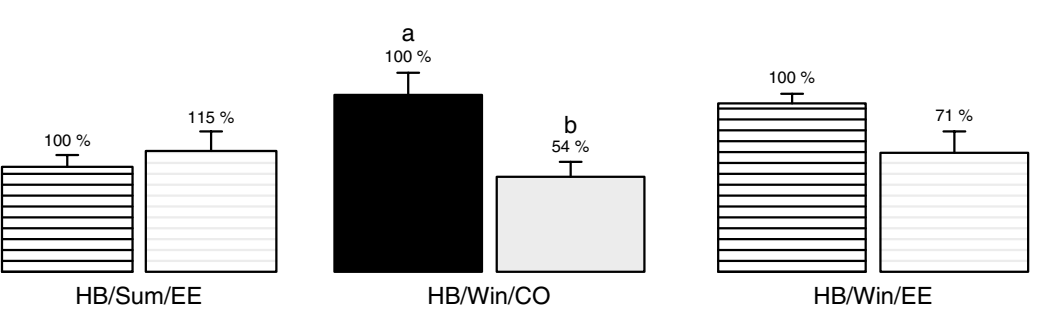

Fig. 10 Average Corallina officinalis (CO-filled bars), and Ellisolandia elongata (EE-lined bars) $\mathrm{rETR}_{\max }, \alpha, E_{k}$ and $F_{\mathrm{v}} / F_{\mathrm{m}}$ at lower shore Heybrook Bay $(H B)$ at the start (black bars) and end (light grey bars) of summer (Sum) and winter (Win) tidal emersion peri-

ods $(n=9 \pm \mathrm{SE})$. Percentages demonstrate $\%$ change in parameters normalized to start emersion values. Letters denote significant differences

Table 5 Multiple linear regression analysis of ETRR $_{\max }$ in relation to irradiance (expressed as irradiance measured) (Irra.), rock pool water temperature (Temp.), and principal components one (PC1) and two (PC2) from PCA of rock pool water carbonate chemistry

\begin{tabular}{|c|c|c|c|c|c|c|c|c|c|c|c|}
\hline \multirow[t]{2}{*}{ Variable } & \multirow[t]{2}{*}{ Intercept } & \multicolumn{4}{|c|}{ Predictor coefficients \pm SE and significance } & \multicolumn{4}{|c|}{ Relative importance } & \multirow[t]{2}{*}{$R^{2}$} & \multirow[t]{2}{*}{ Model $P n$} \\
\hline & & Irra. & Temp. & $\mathrm{PC} 1$ & $\mathrm{PC} 2$ & Irra. & Temp. & $\mathrm{PC} 1$ & $\mathrm{PC} 2$ & & \\
\hline $\mathrm{rETR}_{\max }$ & $122.5 \pm 7.6$ & $-0.025 \pm 0.007 * *$ & $-2.505 \pm 0.693 * * *$ & $-0.509 \pm 1.00$ & $0.017 \pm 2.50$ & $37 \%$ & $45 \%$ & $16 \%$ & $0 \%$ & 0.65 & $<0.0001 \quad 70$ \\
\hline
\end{tabular}

Regression coefficients (intercept and predictors) are displayed \pm standard error (SE) and with associated significance $(* * * P<0.001$; ** $P<0.01 ; * P<0.05$ ), in addition to the relative importance of predictor variables, associated overall model $R^{2}$ and significance (Model $P$ ), and the number of observations $(n)$

Over periods of winter emersion, Corallina photophysiology appeared more sensitive to relatively smaller changes in irradiance than those experienced during summer emersion (supporting our proposal of winter acclimation to low irradiance conditions), and down regulation of photochemistry was less effective over tidal emersion periods. At CM, while similar dynamics in $F_{\mathrm{v}} / F_{\mathrm{m}}$ were observed as during summer, decreases in $F_{\mathrm{v}} / F_{\mathrm{m}}$ at mid emersion were proportionately larger than those during summer and did not serve to maintain $\mathrm{rETR}_{\max }$, which was 


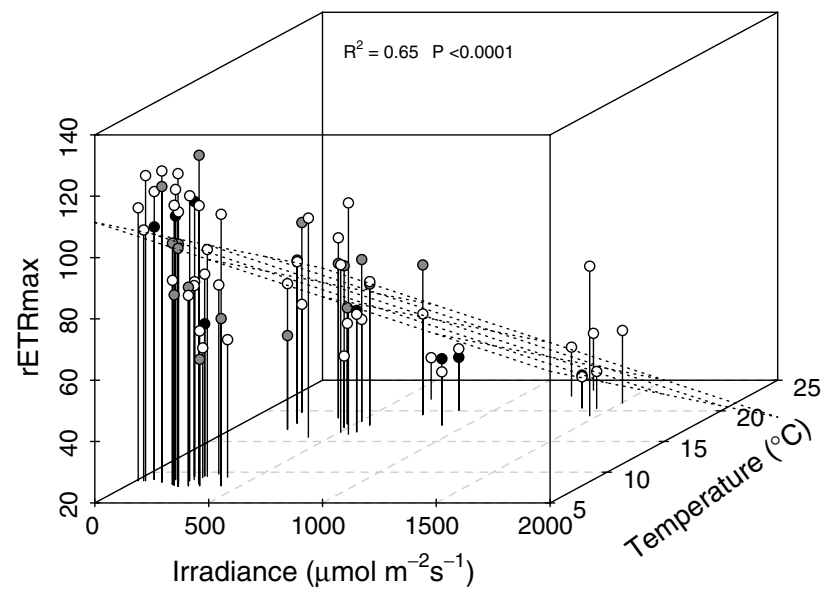

Fig. 11 Multiple linear regression of $\mathrm{rETR}_{\max }$ in relation to irradiance (37\% relative importance) and water temperature (45\% relative importance). Dashed grid demonstrates the regression plane. Corallina officinalis (white circles), Corallina caespitosa (dark grey circles) and Ellisolandia elongata (black circles) data are highlighted

significantly decreased at mid emersion. At HB, both upper and lower shore $C$. officinalis demonstrated significant decreases in $F_{\mathrm{v}} / F_{\mathrm{m}}, \mathrm{rETR}_{\max }$ and $\alpha$ in response to relatively moderate increases in irradiance, with no recovery by the end of emersion in upper shore pools.

Large antennae are necessary for efficient light capture in light limiting conditions, but they can be a liability when light is abundant or excessive (Muller et al. 2001). Low light photoacclimation to winter conditions thus seemed to increase Corallina sensitivity to photostress during tidal emersion periods. In addition, photoinhibition was not as effective in maintaining $\mathrm{rETR}_{\max }$ over winter emersion when irradiance increased. This may be expected given slower acclimation, protein turnover and xanthophyll deepoxidation under low temperature conditions (Franklin and Forster 1997). However, higher rates of rETR $_{\max }$ were still evident overall during winter as compared to summer, suggesting that Corallina and Ellisolandia achieved a balance between the long-term seasonal and short-term tidal emersion requirements for photoacclimation.

Limited evidence for inter-specific variability in photophysiology was observed during the present study. Though higher $F_{\mathrm{v}} / F_{\mathrm{m}}$ was observed for $C$. officinalis at the start of tidal emersion in comparison to $C$. caespitosa at $\mathrm{CM}$, patterns in photophysiology were remarkably similar for the two species, with no other differences observed. Similarly, no significant difference in $C$. officinalis and E. elongata photophysiology was evident at lower shore $\mathrm{HB}$, though on the whole, E. elongata appeared less responsive to changes in abiotic conditions than $C$. officinalis.

Given that the species examined demonstrate both large-scale geographic (Williamson et al. in review; Brodie et al. 2013) and small-scale within-site differences in distribution, differential tolerances to abiotic stressors likely exist. While our data provide information on the photophysiology of Corallina and Ellisolandia in situ under the influence of highly variable abiotic conditions, laboratorybased analyses of photochemistry using steady-state fluorescence techniques, with control/manipulation of abiotic parameters, are required to disentangle underlying species tolerances. This study provides an initial account of the photophysiology for these keystone species in the context of the environment to which they are adapted in the NE Atlantic.

Acknowledgments The authors wish to thank the staff of the UKOARP carbonate chemistry analysis facility at NOC, Southampton. This work was funded by the British Phycological Society and NERC grant (NE/H025677/1).

Open Access This article is distributed under the terms of the Creative Commons Attribution License which permits any use, distribution, and reproduction in any medium, provided the original author(s) and the source are credited.

\section{References}

Andersson AJ, Mackenzie FT (2012) Revisiting four scientific debates in ocean acidification research. Biogeosciences 9:893-905. doi:1 0.5194/bg-9-893-2012

Anthony KRN, Kleypas JA, Gattuso J-P (2011) Coral reefs modify their seawater carbon chemistry-implications for impacts of ocean acidification. Glob Chang Biol 17:3655-3666. doi:10.1111/j. 1365-2486.2011.02510.x

Badger M (2003) The roles of carbonic anhydrases in photosynthetic $\mathrm{CO}_{2}$ concentrating mechanisms. Photosynth Res 77:83-94. doi:1 0.1023/A:1025821717773

Bates D, Maechler M, Bolker B, Walker S (2013) lme4: linear mixedeffects models using Eigen and S4. http://CRAN.R-project.org/ package $=$ lme 4

Björk M, Axelsson L, Beer S (2004) Why is Ulva intestinalis the only macroalga inhabiting isolated rockpools along the Swedish Atlantic coast? Mar Ecol Prog Ser 284:109-116. doi:10.3354/m eps 284109

Brodie J, Walker RH, Williamson C, Irvine LM (2013) Epitypification and redescription of Corallina officinalis L., the type of the genus, and $C$. elongata Ellis et Solander (Corallinales, Rhodophyta). Cryptogam Algol 34:49-56. doi:10.7872/crya.v34.iss1.2013.49

Burdett HL, Hennige SJ, Francis FT-Y, Kamenos NA (2012) The photosynthetic characteristics of red coralline algae, determined using pulse amplitude modulation (PAM) fluorometry. Bot Mar. doi:10.1515/bot-2012-0135

Cao L, Caldeira K, Jain AK (2007) Effects of carbon dioxide and climate change on ocean acidification and carbonate mineral saturation. Geophys Res Lett 34:L05607. doi:10.1029/2006GL028605

Daniel M, Boyden C (1975) Diurnal variations in physico-chemical conditions within intertidal rockpools. Field Stud 4:161-176

Davison I, Pearson G (1996) Stress tolerance in intertidal seaweeds. J Phycol 32:197-211

Dickson AG, Millero FJ (1987) A comparison of the equilibrium constants for the dissociation of carbonic acid in seawater media. Deep Sea Res A Oceanogr Res Pap 34:1733-1743. doi:10.1016/0198-0149(87)90021-5 
Dickson A, Sabine C, Christian J (2007) Guide to best practices for ocean $\mathrm{CO}_{2}$ measurements. PICES Spec Publ 3:1-191

Doney SC (2006) The dangers of ocean acidification. Sci Am 294:58-65

Doney SC (2010) The growing human footprint on coastal and openocean biogeochemistry. Science 328:1512-1516. doi:10.1126/ science. 1185198

Egilsdottir H, Noisette F, Noël LM-LJ et al (2013) Effects of $p \mathrm{CO}_{2}$ on physiology and skeletal mineralogy in a tidal pool coralline alga Corallina elongata. Mar Biol 160:2103-2112. doi:10.1007/ s00227-012-2090-7

Eilers PHC, Peeters JCH (1988) A model for the relationship between light intensity and the rate of photosynthesis in phytoplankton. Ecol Model 42:199-215

Franklin LA, Forster RM (1997) The changing irradiance environment: consequences for marine macrophyte physiology, productivity and ecology. Eur J Phycol 32:207-232. doi:10.1080/09670 269710001737149

Ganning B (1971) Studies on chemical physical and biological conditions in Swedish rockpool ecosystems. Ophelia 9:51-105

Genty B, Briantais JM, Baker NR (1989) The relationship between the quantum yield of photosynthetic electron transport and quenching of chlorophyll fluorescence. Biochim Biophys Acta 990:87-92

Grömping U (2006) Relative importance for linear regression in R: the package relaimpo. J Stat Softw 17:1-27

Häder D-P, Lebert M, Flores-Moya A et al (1997) Effects of solar radiation on the photosynthetic activity of the red alga Corallina elongata Ellis et Soland. J Photochem Photobiol B Biol 37:116202. doi:10.1023/B:PRES.0000004300.20503.18

Häder D-P, Lebert M, Walter Helbling E (2003) Effects of solar radiation on the patagonian Rhodophyte Corallina officinalis (L.). Photosynth Res 78:119-132. doi:10.1023/B:PRES.0000004300.20503.18

Harley CDG, Anderson KM, Demes KW et al (2012) Effects of climate change on global seaweed communities. J Phycol 48:10641078. doi:10.1111/j.1529-8817.2012.01224.x

Hind KR, Saunders GW (2013) A molecular phylogenetic study of the Tribe Corallineae (Corallinales, Rhodophyta) with an assessment of genus-level taxonomic features and descriptions of novel genera. J Phycol 49:103-114. doi:10.1111/jpy.12019

Hofmann GE, Smith JE, Johnson KS et al (2011) High-frequency dynamics of ocean pH: a multi-ecosystem comparison. PLoS ONE 6:e28983. doi:10.1371/journal.pone.0028983

Hofmann LC, Yildiz G, Hanelt D, Bischof K (2012) Physiological responses of the calcifying rhodophyte, Corallina officinalis (L.), to future $\mathrm{CO}_{2}$ levels. Mar Biol 159:783-792. doi:10.1007/ s00227-011-1854-9

Hofmann LC, Straub S, Bischof K (2013) Elevated $\mathrm{CO}_{2}$ levels affect the activity of nitrate reductase and carbonic anhydrase in the calcifying rhodophyte Corallina officinalis. J Exp Bot 64:899-908. doi:10.1093/jxb/ers369

Hofmann GE, Evans TG, Kelly MW et al (2014) Exploring local adaptation and the ocean acidification seascape-studies in the California Current Large Marine Ecosystem. Biogeosciences 11:1053-1064. doi:10.5194/bg-11-1053-2014

Hurd CL, Cornwall CE, Currie K et al (2011) Metabolically induced $\mathrm{pH}$ fluctuations by some coastal calcifiers exceed projected 22nd century ocean acidification: a mechanism for differential susceptibility? Glob Chang Biol 17:3254-3262. doi:10.1111/j.1365-2486.2011.02473.x

Invers O, Romero J, Perez M (1997) Effects of $\mathrm{pH}$ on seagrass photosynthesis: a laboratory and field assessment. Aquat Bot 59:185-194

Irvine LM, Chamberlain YM (1994) Seaweeds of the British Isles, vol 1. Rhodophyta. Part 2B. Corallinales, Hildenbrandiales. HMSO, London
Israel A, Hophy M (2002) Growth, photosynthetic properties and Rubisco activities and amounts of marine macroalgae grown under current and elevated seawater $\mathrm{CO}_{2}$ concentrations. Glob Chang Biol 8:831-840

Johansen HW (1981) Coralline algae: a first synthesis. CRC Press, Boca Raton, Florida, p 239. ISBN 0-8493-5261-4

Jones CG, Lawton JH, Shachak M (1994) Organisms as ecosystem engineers. Oikos 69:373-386. doi:10.2307/3545850

Kelly MW, Padilla-Gamiño JL, Hofmann GE (2013) Natural variation and the capacity to adapt to ocean acidification in the keystone sea urchin Strongylocentrotus purpuratus. Glob Chang Biol 19:2536-2546. doi:10.1111/gcb.12251

Larsson C, Axelsson L (1999) Bicarbonate uptake and utilization in marine macroalgae. Eur J Phycol 34:79-86

Lobban CS, Harrison PJ (1994) Seaweed ecology and physiology. Cambridge University Press, New York, p 366

Luning K (1990) Seaweeds: their environment, biogeography and ecophysiology. Wiley, New York, p 527

Manzello DP, Enochs IC, Melo N et al (2012) Ocean acidification refugia of the Florida Reef Tract. PLoS ONE 7:e41715. doi:10.1371/journal.pone.0041715

Martins GM, Hawkins SJ, Thompson RC, Jenkins SR (2007) Community structure and functioning in intertidal rock pools: effects of pool size and shore height at different successional stages. Mar Ecol Prog Ser 329:43-55

Mehrbach C, Culberson CH, Hawley JE, Pytkowicz RM (1973) Measurement of the apparent dissociation constants of carbonic acid in seawater at atmospheric pressure. Limnol Oceanogr 18:897-907

Middelboe A, Hansen P (2007a) High pH in shallow-water macroalgal habitats. Mar Ecol Prog Ser 338:107-117. doi:10.3354/m eps338107

Middelboe A, Hansen P (2007b) Direct effects of pH and inorganic carbon on macroalgal photosynthesis and growth. Mar Biol Res 3:134-144. doi:10.1080/17451000701320556

Morris S, Taylor AC (1983) Diurnal and seasonal-variation in physicochemical conditions within intertidal rock pools. Estuar Coast Shelf Sci 17:339-355. doi:10.1016/0272-7714(83)90026-4

Muller P, Xiao-ping L, Niyogi KK (2001) Update on photosynthesis non-photochemical quenching. A response to excess light energy 1. Plant Physiol 125:1558-1566

Nelson WA (2009) Calcified macroalgae - critical to coastal ecosystems and vulnerable to change: a review. Mar Freshw Res 60:787. doi:10.1071/MF08335

Noisette F, Egilsdottir H, Davoult D, Martin S (2013) Physiological responses of three temperate coralline algae from contrasting habitats to near-future ocean acidification. J Exp Mar Bio Ecol 448:179-187. doi:10.1016/j.jembe.2013.07.006

Perkins RG, Mouget J-L, Lefebvre S, Lavaud J (2006) Light response curve methodology and possible implications in the application of chlorophyll fluorescence to benthic diatoms. Mar Biol 149:703-712. doi:10.1007/s00227-005-0222-z

Perkins RG, Kromkamp JC, Serôdio J et al. (2010) Chlorophyll a fluorescence in aquatic sciences: methods and applications. doi:10.1007/978-90-481-9268-7

Pierrot D, Lewis E, Wallace DWR (2006) MS Excel program developed for $\mathrm{CO}_{2}$ system calculations. ORNL/CDIAC-105a. Carbon Dioxide Information Analysis Center, Oak Ridge National Laboratory, US Department of Energy, Oak Ridge. doi:10.3334/CDIAC/otg.CO2SYS_XLS_CDIAC105a

R Core Team (2013) R: a language and environment for statistical computing

Ralph PJ, Gademann R (2005) Rapid light curves: a powerful tool to assess photosynthetic activity. Aquat Bot 82:222-237. doi:10.1016/j.aquabot.2005.02.006

Saderne V, Fietzek P, Herman PMJ (2013) Extreme variations of $p \mathrm{CO}_{2}$ and $\mathrm{pH}$ in a macrophyte meadow of the Baltic Sea in summer: 
evidence of the effect of photosynthesis and local upwelling. PLoS ONE 8:e62689. doi:10.1371/journal.pone.0062689

Semesi IS, Kangwe J, Björk M (2009) Alterations in seawater pH and $\mathrm{CO}_{2}$ affect calcification and photosynthesis in the tropical coralline alga, Hydrolithon sp. (Rhodophyta). Estuar Coast Shelf Sci 84:337-341. doi:10.1016/j.ecss.2009.03.038

Tremblay A, Ransijn J (2013) LMERConvenienceFunctions: A suite of functions to back-fit fixed effects and forward-fit random effects, as well as other miscellaneous functions. http://cran.r-project.org/ web/packages/LMERConvenienceFunctions/index.html

Truchot J-P, Duhamel-Jouve A (1980) Oxygen and carbon dioxide in the marine intertidal environment: diurnal and tidal changes in rockpools. Respir Physiol 39:241-254. doi:10.1016/0034-5687(80)90056-0

Venables WN, Ripley BD (2002) Modern applied statistics with S, 4th edn. Springer, New York
Walker RH, Brodie J, Russell S et al (2009) Biodiversity of coralline algae in the northeastern Atlantic including Corallina caespitosa. nov. (Corallinoideae, Rhodophyta). J Phycol 45:287-297. doi:10.1111/j.1529-8817.2008.0637.x

Williamson C, Walker R, Robba L et al (in review) Towards resolution of diversity in Corallina (Corallinales, Rhodophyta) and related genera. Phycologia

Wolfe K, Dworjanyn SA, Byrne M (2013) Effects of ocean warming and acidification on survival, growth and skeletal development in the early benthic juvenile sea urchin (Heliocidaris erythrogramma). Glob Chang Biol 19:2698-2707. doi:10.1111/gcb.12249

Wootton JT, Pfister CA, Forester JD (2008) Dynamic patterns and ecological impacts of declining ocean $\mathrm{pH}$ in a high-resolution multi-year dataset. Proc Natl Acad Sci USA 105:18848-18853. doi:10.1073/pnas.0810079105 